\title{
NGF Improves Spatial Memory in Aged Rodents as a Function of Age
}

\author{
W. Fischer, ${ }^{1}$ A. Björklund, ${ }^{1}$ K. Chen, ${ }^{2}$ and F. H. Gage ${ }^{2}$ \\ 'Department of Medical Cell Research, University of Lund, 22362 Lund, Sweden and 'Department of Neurosciences, \\ University of California at San Diego, La Jolla, California 92037
}

\begin{abstract}
Aged rats were tested for place navigation in a circular water maze for spatial memory ability at 18 and $\mathbf{3 0}$ months of age; $45 \%$ of the 18-month-old rats displayed impaired place navigation performance relative to young control rats, while essentially all of the 30-month-old rats were impaired. The aged impaired rats were retested twice during NGF or vehicle infusion in the right lateral ventricle. In the 18-month-old group, NGF-infused rats showed improved retention of previously acquired place navigation performance and improved spatial acuity over the former platform site when the invisible platform was removed. NGF infusion also had a significant effect in the much more severely impaired 30 month-old rats: while the vehicle-infused aged rats showed a progressive decline in the performance between the first and second test weeks, the performance of the NGF-infused rats remained stable throughout the infusion period. The interpretation of these effects in the oldest animals, however, was confounded by a progressive decline in swim speed seen in the vehicle-infused animals.
\end{abstract}

The 30-month-old vehicle-infused control rats showed a significant cell loss and cell shrinkage relative to the young control rats in the septal/diagonal band area, the striatum, and the nucleus basalis as assessed by NGF-receptor (NGFr) and ChAT double-label immunocytochemistry. A significant increase in the size but not in the number of cells was observed on the side of the NGF infusion in the 30-month-old NGF-infused rats. While there was no significant decrease in the size or number of labeled cells in any of the 18-monthold rats, the ChAT-positive neurons in the 18-month-old NGFinfused rats showed significant hypertrophy on the side of the NGF infusion.

These results indicate that the effect of exogenous NGF on spatial memory performance is more pronounced in younger impaired (18-month-old) animals than in those of more advanced age, and that a morphological response to NGF can be obtained not only in older animals where cholinergic neuronal shrinkage and cell loss occurs, but also in young impaired rats where cholinergic cellular atrophy has not yet

\footnotetext{
Received Sept. 12, 1990; revised Jan. 15, 1991; accepted Jan. 22, 1991.

We wish to thank Donna Okino, Alicja Flasch, Ulla Jarl, Sten Nilsson, and Agneta Othberg for excellent technical assistance, Agneta Persson for photographic work, Ragnar Mårtensson for valuable help with the diagrams, and Stefan Seth for help in the design of the morphometric analysis. We also thank Sheryl Christenson and Siv Carlson for secretarial assistance. This study was supported by grants from the Swedish Medical Research Council, the National Institute of Aging (AG 06088), the Pew Memorial Trust, and the Greta and Johan Kock Foundation.

Correspondence should be addressed to Walter Fischer, Department of Medical Cell Research, University of Lund, Biskopsgatan 5, 22362 Lund, Sweden.
}

Reprint requests should be addressed to Dr. F. H. Gage, at the above address. Copyright $(\odot) 1991$ Society for Neuroscience 0270-6474/91/111889-18\$03.00/0 evolved. The results are compatible with the idea that the behavioral effects of intraventricular NGF infusion are mediated, at least in part, via the cholinergic/NGFr-positive neurons in the forebrain.

Mammalian CNS tissues have been shown to produce and contain NGF, as revealed by a variety of techniques, including NGF mRNA by Northern blotting and in situ hybridization (Ayer Lelievre et al., 1983; Korsching et al., 1985; Large et al., 1986; Shelton and Reichardt, 1986; Whittemore et al., 1986; Lärkfors et al., 1987a,b), NGF antigen by immunohistochemistry and enzyme immunoassay (Ayer Lelievre et al., 1983; Korsching et al., 1985; Whittemore et al., 1986), and NGF activity by bioassay (Scott et al., 1981; Collins and Crutcher, 1985). The highest levels of NGF in CNS tissue appear within the hippocampus and cortex, that is, the target areas of the cholinergic basal forebrain system (Korsching et al., 1985; Shelton and Reichardt, 1986; Whittemore et al., 1986). NGF receptors (NGFr), as revealed by immunohistochemistry to the low-affinity receptor (Taniuchi and Johnson, 1985), are located on the cholinergic neurons in the basal forebrain (Richardson et al., 1986; Taniuchi et al., 1986; Springer et al., 1987; Batchelor et al., 1989; Pioro and Cuello, 1990), which suggests that this system is a preferential target for NGF in the brain. NGF administered into rat brain raises ChAT levels in the hippocampus, septum, and striatum (Hefti et al., 1984; Mobley et al., 1985). Recently, several groups (Hefti, 1986; Williams et al., 1986; Kromer, 1987; Gage et al., 1988; Montero and Hefti, 1988) have independently reported that intraventricular administration of purified NGF into adult rats from the time of fimbria-fornix transection onward prevents the atrophy or loss of most of the axotomized cholinergic neurons in the septum/diagonal band area.

Previous studies (Hornberger et al., 1985; Biegon et al., 1986; Luine et al., 1986; Gilad et al., 1987; Altavista et al., 1988; Fischer et al., 1989) have shown that the basal forebrain cholinergic system undergoes degenerative changes with age in rodents. In addition, recent studies have reported that aged rats have significant decreases in number and size of NGFr-immunoreactive cells in the hasal forebrain using the monoclonal antibody 192-IgG (Koh and Loy, 1988; Markram and Segal, 1990). Furthermore, we have recently shown that shrinkage and loss of AChE-positive cells in the basal forebrain nuclei and the striatum are correlated with the extent of spatial memory impairments in 2-yr-old female Sprague-Dawley rats (Fischer et al., 1989).

A link between age-related impairments in cognitive function, NGF, and the atrophy of basal forebrain cholinergic neurons is suggested by the observation that chronic intraventricular infusion of NGF can reduce cholinergic neuronal atrophy and 


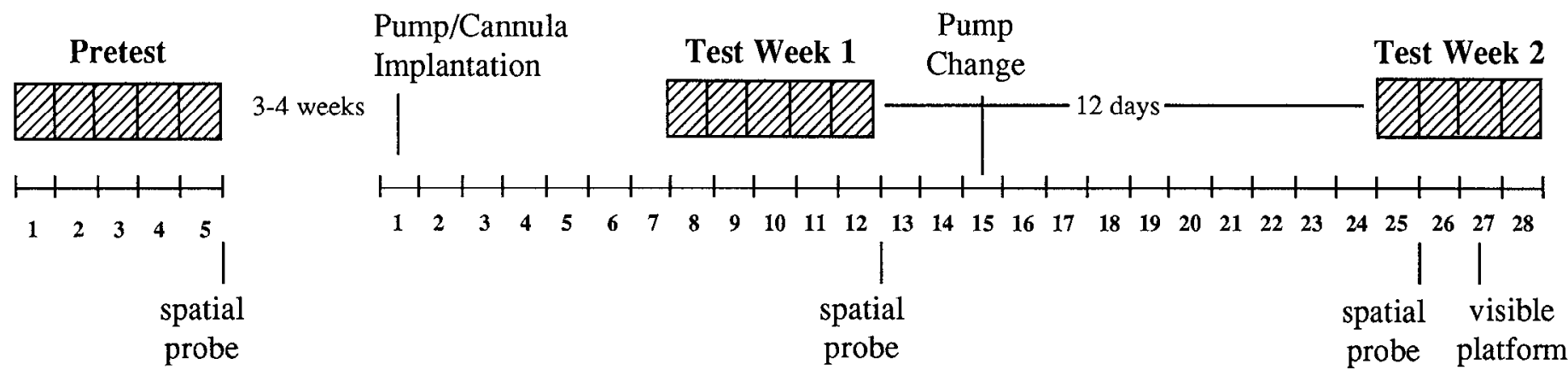

Figure 1. Schematic drawing of the experimental plan. The rats were screened for spatial memory performance in the pretest. The time interval between the pretest and the implantation of cannulas connected to osmotic minipumps was, at the most, 3 (for the 30-month group) or 4 (18month group) weeks. Changing of pumps filled with new NGF or vehicle solution occurred on the fifteenth day of infusion. Note that the spatial probe test was located after the eighth swim trial on the last day of testing in the pretest and test week 1 , but on the first day in test week 2 .

improve spatial memory retention in impaired aged rats (Fischer et al., 1987). In this study, aged Sprague-Dawley rats (2224 months old) that were impaired in a pretest on the Morris water maze were divided into two groups, an experimental group and a control group. Two months after the pretest, the rats in the experimental group received continuous infusions of NGF for $28 \mathrm{~d}$ via cannulas that were chronically implanted into the lateral ventricle. During the second and fourth weeks of infusion, the rats were retested on the water maze. The performance of the aged impaired rats in both groups remained impaired compared to nonimpaired aged rats during the first retest. However, by the second retest, the NGF-treated animals, but not the control aged impaired rats, had improved to the level of nonimpaired aged rats on measures of escape latency and distance to find the platform. This improvement was due primarily to improved retention of the performance acquired in the first retest. Furthermore, in the NGF-treated rats, AChE-positive cell bodies in the basal forebrain on the side of NGF infusion were significantly increased in size. These results indicated that continuous intracerebral infusion of NGF over a period of 4 weeks could partly reverse the cholinergic cell body atrophy and improve retention of a spatial memory task in bchaviorally impaired aged rats.

This study supports the notion that NGF may be involved in the age-related degenerative changes in central cholinergic neurons. The objective of the present study was to extend these initial findings in two ways. First, in the previous study we used AChE histochemistry in the morphological characterization of cholinergic cells; in the present study we used a double-labeling method developed for assessing colocalization of ChAT and NGFr (Batchelor et al., 1989). Second, we wished to determine whether the effects of NGF on the spatial memory impairments in aged rats are age dependent. To this end, we have infused NGF in rats at 18 and 30 months of age rather than in 24month-old rats as in our first study.

\section{Materials and Methods}

\section{Animals}

Fcmalc Sprague-Dawley rats (ALAB, Stockholm) were obtained as retired breeders at 10-12 months of age and were housed for an additional $6(n=55)$ or 18 months $(n=38)$ before the beginning of the experiment. Young female control rats were bought at 2 months of age and housed for another 4 weeks before the beginning of the tests. The aged rats were housed five animals per cage, and the young were housed eight per cage in a 12-hr:12-hr light/dark cycle. Behavioral testing was performed during the daylight period.

\section{Preimplantation behavioral testing}

The rats were tested in a circular Morris water maze (Morris, 1981), $120 \mathrm{~cm}$ in diameter and $45 \mathrm{~cm}$ in height, filled with water to a depth of $30 \mathrm{~cm}$. Dried milk powder was added to make the water opaque. An escape platform was placed $1 \mathrm{~cm}$ beneath the water surface and kept in a constant position in the pool during all the trials. The room in which the pool was situated was rich in extramaze cues (e.g., pictures, window, plants, experimenter's desk). Four equally spaced points around the edge of the pool were used as start positions. The screening of the rats in the pretest was performed in two blocks of four trials on each day for five consecutive days. After the last swim trial on the fifth day, the platform was removed, and the swim path and the distance swum in each of the four quadrants were recorded over $60 \mathrm{sec}$ (spatial probe trial). The number of times the rats swam through the area where the platform had been situated were measured as "platform crossings."

Eighteen-month group. A total of 55 aged (18 months old) and nine young ( 3 months old) animals were tested in the water maze. If the latency (during the last $2 \mathrm{~d}$ of testing) of an aged animal to find the hidden platform exceeded the value of two standard deviations from the mean performance of the young group, the rat was denoted "cognitively impaired" (Gage and Björklund, 1986). Impairment in performance compared to the young animals was found in about $45 \%$ of the 18 -month-old rats in the water maze task. About $33 \%$ were found to perform within, or better than, one standard deviation of the mean performance of the young rats. This latter group of rats was denoted "nonimpaired." The cognitively impaired aged rats were randomly allocated to an NGF-infused $(n=13)$ and a vehicle-infused $(n=12)$ group, whereas the aged animals selected to the nonimpaircd group ( $n$ $=6$ ) remained nonoperated.

Thirty-month group. A total of 38 aged ( 30 months old) and six young ( 3 months old) animals were screened for their ability to perform in the water maze. Impairment in the water maze task was found in over $90 \%$ of the 30-month-old rats, using the same criteria as for the 18 -monthold rats. Of the impaired 30 -month-old rats, 22 animals were randomly allocated to an NGF-infused $(n=11)$ and a vehicle-infused $(n=11)$ group.

\section{Surgery}

The 47 behaviorally impaired aged rats had a cannula implanted unilaterally into the right lateral ventricle (anteroposterior, $+0.7 \mathrm{~mm}$ from bregma; mediolateral, $-1.2 \mathrm{~mm}$ from bregma; dorsoventral, $-4.5 \mathrm{~mm}$ from the dura). The cannula was connected to an Alzet model 2002 osmotic minipump placed subcutaneously in the dorsal neck/back area (see Williams et al., 1986). The osmotic minipumps delivered the solutions at an infusion rate of $0.5 \mu \mathrm{l} / \mathrm{hr}$.

Twelve rats in the 18-month-old group and 11 rats in the 30-monthold group were implanted with pumps filled with an infusion vehicle containing PBS (pH, 7.4) and $0.1 \%$ autologous rat serum (vehicle-infused group). Thirteen 18-month-old rats and 11 30-month-old rats were implanted with pumps filled with NGF $(25 \mu \mathrm{g} / \mathrm{ml} ; 2.5 \mathrm{~S}$, from mouse salivary gland) dissolved in the same vehicle (NGF-infused group). The pumps were changed once (after $15 \mathrm{~d}$ of continuous infusion), and the rats were killed for immunocytochemistry after $28 \mathrm{~d}$ of continuous infusion. 


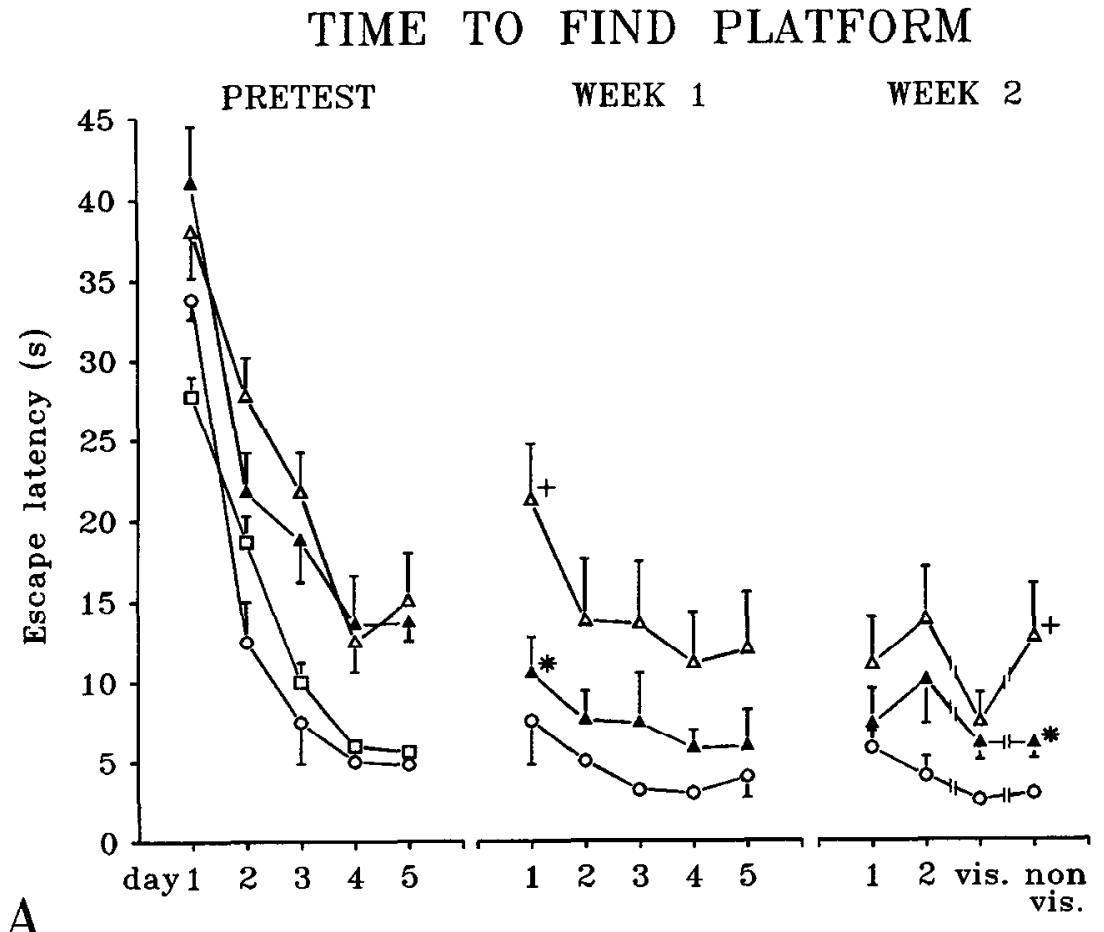

A

DISTANCE

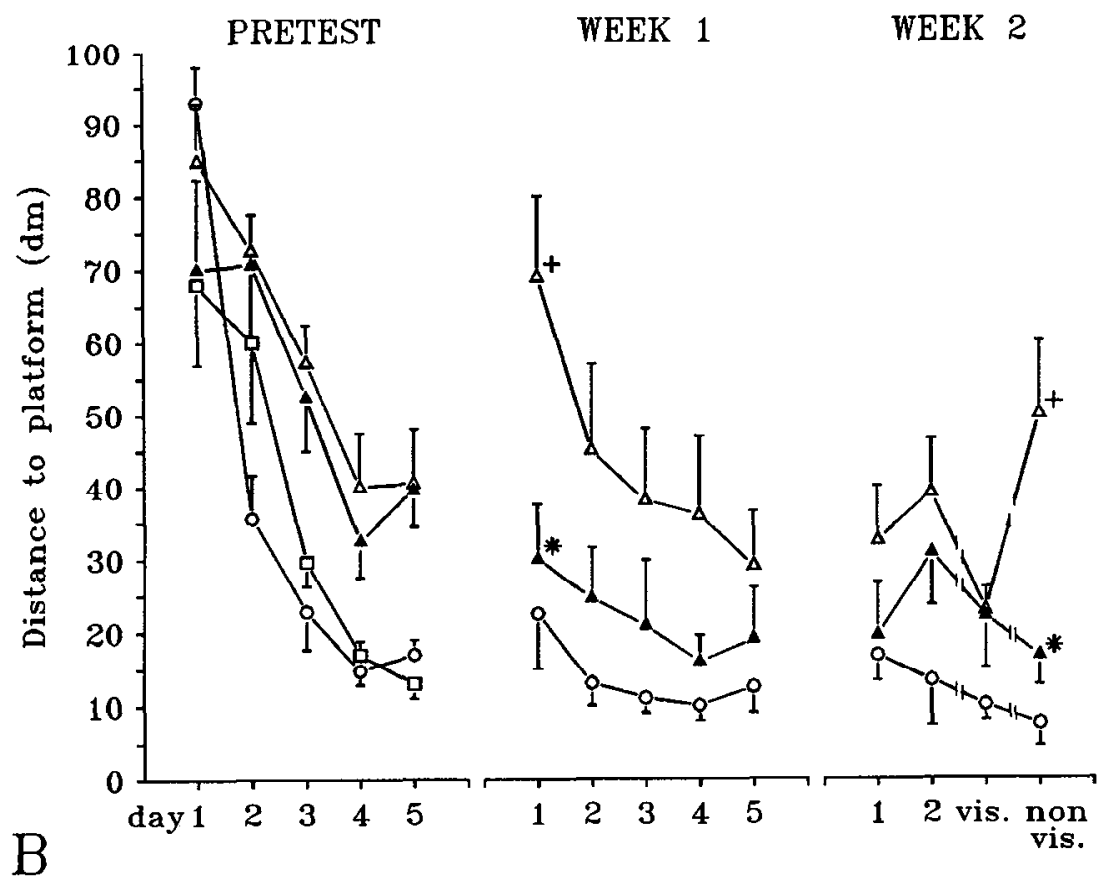

Figure 2. Spatial memory performance of 18-month-old rats in the Morris water maze (mean \pm SEM) as measured by the time it took the rats to find the platform (escape latency in seconds; $A$ ) and the distance swum before finding the hidden platform (in decimeters; $B$ ). Cannulas connected to osmotic minipumps filled with either NGF or vehicle solution were only inserted in the aged impaired groups (between the pretest and test week 1, i.e., $7 \mathrm{~d}$ before day 1 in test week 1; see Fig. 1). On the first test day in test week 1 , the NGF-treated animals performed as well as they did at the end of the pretest (i.e., days 4 and 5), whereas the vehicleinfused animals showed significant forgetting $(+, p<0.05$, two-way ANOVA with post hoc Student's related $t$ test). Thus, on the first day in test week 1, the NGF-treated rats performed significantly better than the vehicle-infused animals $\left(^{*}, p<0.05\right.$, one-way ANOVA with post hoc Fisher PLSD; see $A$ and $B$ ) and were no longer significantly different in performance from the aged nonimpaired group. Note that the time interval that separated the pretest and test week 1 was $24 \pm 1 \mathrm{~d}$ for the aged NGF-infused, $20 \pm 2 \mathrm{~d}$ for the aged vehicle-infused, and $18 \pm 2 \mathrm{~d}$ for the aged nonimpaired animals. In test week 2 , the vehicle-infused aged animals again showed significant forgetting of the previously acquired performance for both measures between day 3 (visible platform) and day 4 (nonvisible platform;,$+ p<0.05$, two-way ANOVA with post hoc Student's related $t$ test). Thus, on day 4 the NGF-treated and the nonimpaired aged rats performed significantly better than the vehicle-infused aged animals $\left(^{*}, p<0.05\right.$, oneway ANOVA with post hoc Fisher PLSD).

\section{Postimplantation behavioral testing}

Following implantation of cannulas attached to osmotic minipumps, the impaired aged rats recovered for 1 week before again being tested on the water maze task (see Fig. 1, a schematic for temporal ordering of the test). The young control rats were not tested further in the water maze after the pretest. A group of six cognitively nonimpaired aged rats from the 18-month-old group was tested in parallel with the impaired aged animals. During the infusion period $(28 \mathrm{~d})$, the aged rats were retested twice in the Morris water maze: between day 8 and day 12 (test week 1) and between day 25 and day 28 (test week 2; see Fig. 1).

The pretest (described above in Preimplantation behavioral testing) 


\section{Platform crossings}

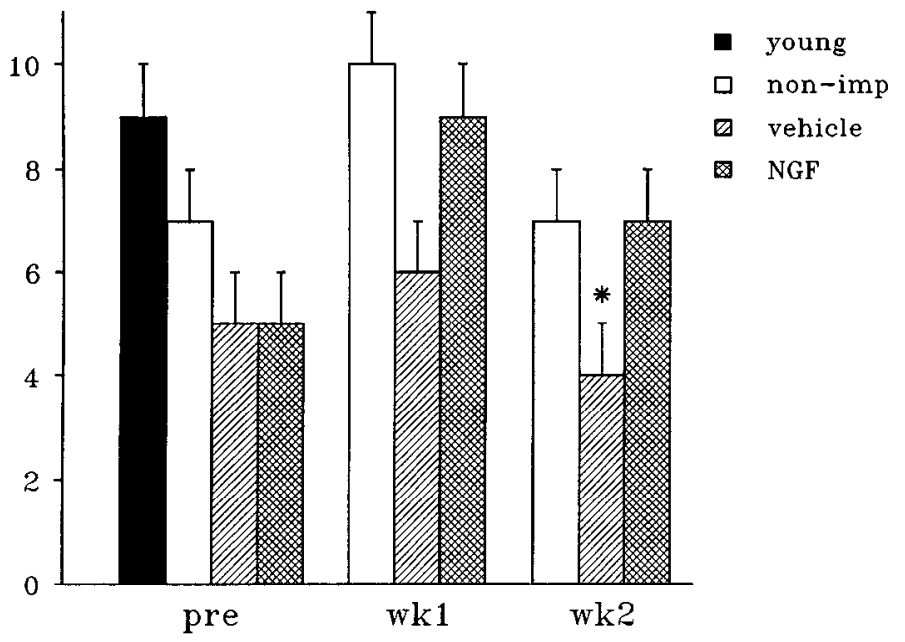

Figure 3. Eighteen-month-old animals. The spatial probe trial was performed on the last day in the pretest and test week 1 (day 5 of testing), whereas in test week 2 the spatial probe trial was performed on the first day of testing (see Materials and Methods). On the last day in the pretest as well as in test week 1 , all groups had learned the task, and no significant difference in performance between the groups could be detected (values represent mean $\Perp$ SEM). However, on the first day of test week 2 , the NGF-treated impaired animals performed significantly better compared to the vehicle-infused impaired animals $(p<0.05$, one-way ANOVA with post hoc Fisher PLSD) and were not significantly different in performance from the nonimpaired (nonoperated; non-imp) animals. Note that a time interval of $12 \mathrm{~d}$ separated the two spatial probe trials in test weeks 1 and 2 . The young animals (solid bar) were only included in the pretest.

ended with a spatial probe trial (on the fifth day, after the eighth swim trial; see Fig. 1), in which the platform was removed and the number of times the rat swam over the former platform site was counted as "platform crossings." The spatial probe trial was repeated on the last day of testing in test week 1 (on the twelfth day of continuous infusion; Fig. 1) and again on the first test day in test week 2 . On the third day in test week 2, a 3-cm-high platform was put on top of the hidden platform to make it visible, to test whether a visible platform would help the impaired rats to perform the task. On the fourth (and final) test day in test week 2 , the platform was again made invisible to the rats (see Fig. 1).

\section{Immunohistochemistry}

After $28 \mathrm{~d}$ of continuous infusion, all rats were prepared for histochemical analysis by transcardial perfusion with $4 \%$ phosphate-buffered paraformaldchydc. The brains were postfixed in the same solution for about $20 \mathrm{hr}$ and then transferred in 20\% sucrose (in PBS) for about $12 \mathrm{hr}$. They were then sectioned coronally in a freezing microtome at $40 \mu \mathrm{m}$ throughout the forebrain. Every fifth section from the brains of the 30month group and every fourth section from those of the 18-month group were used for immunostaining with a double-labeling protocol (see Batchelor et al., 1989). The sections were incubated with a monoclonal antibody specific for NGFr (192-IgG; see Taniuchi et al., 1986; courtesy of E. M. Johnson) with a mixture of $0.25 \%$ Triton X-100 and $1 \%$ serum in $0.1 \mathrm{M}$ Tris-buffered saline. They were incubated with the primary antibody for $16 \mathrm{hr}$ at room temperature and then with a rat-adsorbed horse anti-mouse biotinylated IgG for $3 \mathrm{hr}$ (Vector). The sections were incubated in complexes of avidin and biotinylated peroxidase (Vector) and, finally, reacted in $0.025 \%$ diaminobenzidine, $0.01 \% \mathrm{H}_{2} \mathrm{O}_{2}$, and $0.04 \%$ nickel chloride in Tris-buffered saline $(\mathrm{pH}, 7.45)$. The nickel salt intensification resulted in a black reaction product.

To double label for choline acetyltransferase (ChAT) on the same sections, residual peroxidase enzyme activity had to be blocked by incubation of the sections in $0.6 \% \mathrm{H}_{2} \mathrm{O}_{2}$ solution for $45 \mathrm{~min}$. In addition, free biotinylated binding sites were blocked by the sequential application of excess avidin and biotin (Vector). Following these two blocking procedures, the sections were incubated for $18 \mathrm{hr}$ at room temperature with polyclonal ChAT antibody raised in rabbit (courtesy of L. Hersh). Sections were then incubated for $46 \mathrm{hr}$ in affinity-purified biotinylated donkey anti-rabbit IgG (preadsorbed against rat, human, and mouse immunoglobulins; Amersham). Next, the sections were incubated for 2 $\mathrm{hr}$ in complexes of avidin and biotinylated peroxidase (Vector) and reacted for $25 \mathrm{~min}$ in a solution consisting of $89.5 \mathrm{ml} \mathrm{PBS}(\mathrm{pH}, 7.4)$, $10 \mu \mathrm{l} 1 \%$ ammonium carbonate, and $500 \mu \mathrm{l} 0.1 \% \mathrm{l}$-naphthol (dissolved in ethanol). After a brief wash, the sections were incubated for $10 \mathrm{~min}$ in a $0.1 \%$ buffered pyronin B solution to give a violet reaction product.

\section{Image analysis}

A computerized image analysis technique was used for the morphometric analysis (IBAS II instrument, Zeiss-Kontron) of size and number of double-labeled (NGFr + ChAT) and single-labeled (ChAT) neurons. No single-labclcd NGFr-positive cells could be detected in the areas measured. Medial septum (MS) and the vertical limb of the diagonal band of Broca (VDB) were measured from the level of the genu of the corpus callosum rostrally to the level of the crossing of the anterior commissure caudally. The boundary between MS and VDB was defined as the anterior commissure, and the lateral border of the VDB was set at the medial border of the olfactory tubercle. The area included in the striatum covered the entire cross-sectional area of the head of the caudate-putamen down to the level of the anterior commissure, starting rostrally at the level of the genu of the corpus callosum and ending caudally at the level of the crossing of the anterior commissure. Nucleus basalis magnocellularis (NBM) was defined as the immunolabeled neurons located in the globus pallidus and the adjoining part of the internal capsule. The NBM neurons were measured from the level of the cauda scptum, rostrally to the level of the tail of the caudate-putamen. The numbers of measured sections in the 18-month group were about eight for MS, VDB, and striatum and about 12 for NBM and, in the 30 month group, were about six for the MS, VDB, and the striatum and about 10 for the NBM. Cells were defined (under $10 \times$ objective magnification) as immunolabeled cell bodies with a diameter of $>8 \mu \mathrm{m}$ along the minor axis and a cross-sectional area $>70 \mu \mathrm{m}^{2}$. These criteria were used to avoid excluding any population of small, atrophied immunolabeled neurons. Because double-labeled neurons (NGFr + ChAT) had a brownish appearance and the single-labeled neurons (ChAT) appeared violet, these neuronal populations could be easily distinguished by the observer and then analyzed in the image analysis program. In the NGF-treated animals of the 18-month group, a high background staining occurred in all animals in the septal/diagonal band area. Thus, morphometry of neurons in MS and VDB could not be performed in these NGF-treated animals.

Cell counts are presented in terms of corrected cell numbers using the Abercrombie (1946) formula (see Fischer et al., 1989). In the correction procedure, the setting on the microtome $(40 \mu \mathrm{m})$ was used as the section thickness. In the 18-month group, the thickness of the mounted sections after processing was $10.1 \pm 0.7 \mu \mathrm{m}$ in the young group, 10.8 $\pm 0.4 \mu \mathrm{m}$ in the vehicle-infused group, and $10.1 \pm 0.7 \mu \mathrm{m}$ in the NGFtreated group. The thickness of the mounted sections after processing in the 30-month group was $12.1 \pm 0.9 \mu \mathrm{m}$ in the young group, $12.7 \pm$ $1.2 \mu \mathrm{m}$ in the aged nonimpaired group, $11.6 \pm 0.9 \mu \mathrm{m}$ in the vehicleinfused group, and $12.3 \pm 1.0 \mu \mathrm{m}$ in the NGF-treated group.

\section{Statistical evaluation}

Data given represent mean \pm SEM values. From group analysis and statistical comparison of the results in the water maze, two-way ANOVA with post hoc Student's related $t$ test or one-way ANOVA with post hoc Fisher PLSD was used. In the evaluation of the results of the morphometric analysis, either one-way ANOVA with post hoc Fisher PLSD or Student's rclated $t$ test was used. Statistical significance was accepted at $p<0.05$. Given the small numbers of animals that survived the entire test in each group, we were unable to perform correlational analyses.

\section{Results}

In the 18-month group, one NGF-treated animal died shortly after surgery, and four died during test week 1 due to infections, possibly combined with age-related somatic dysfunctions and stress. On histological examination, two rats were found to have large abscesses in the right hemisphere around the cannula site. In the vehicle-infused group, three animals died during test week 


\section{TIME TO FIND PLATFORM}

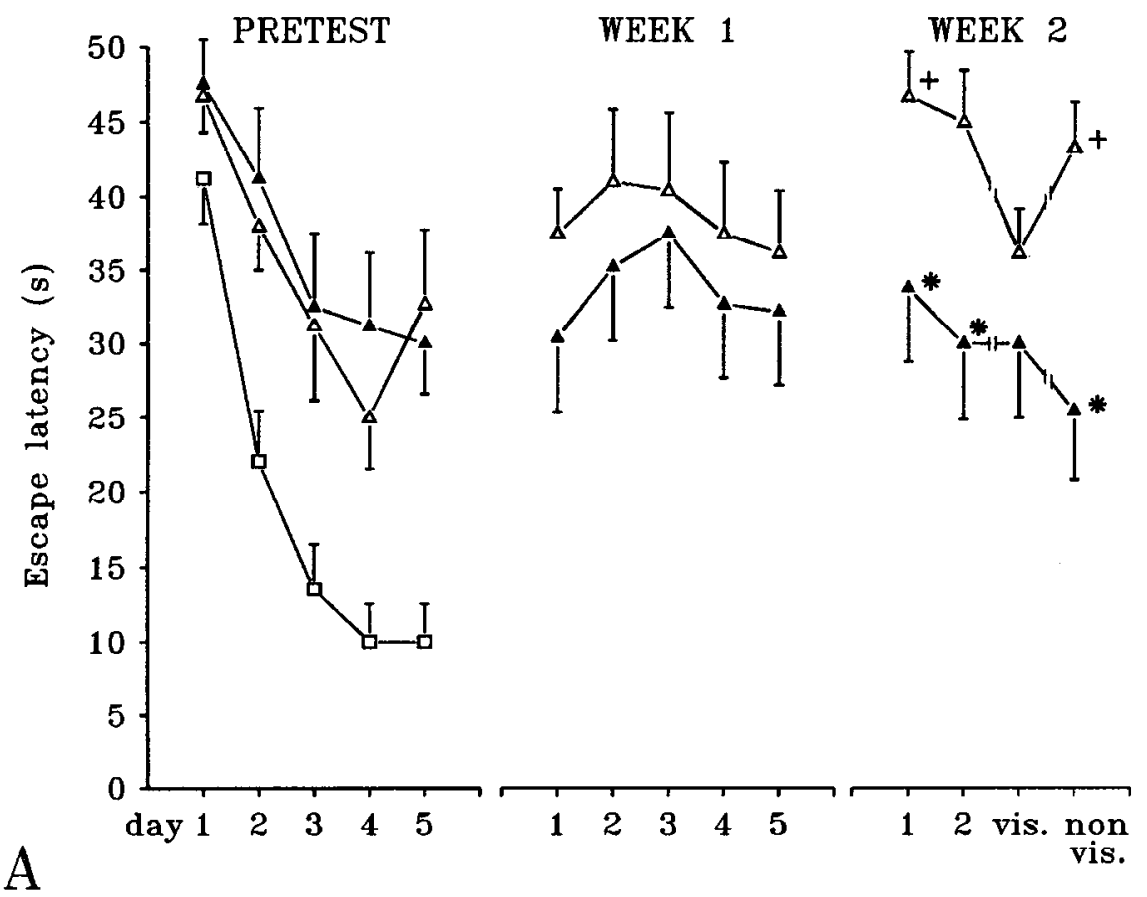

Figure 4. Spatial memory performance of 30-month-old rats in the Morris water maze as measured by the time it took the rats to find the platform (escape latency in seconds; $A$ ) and the distance swum before finding the hidden platform (in decimeters; $B$; mean \pm SEM values). Cannulas connected to osmotic minipumps filled with either NGF or vehicle solution were only inserted in the aged rat groups (between the pretest and test week 1 , i.e., $7 \mathrm{~d}$ before day 1 in test week 1; see Fig. 1). On the first day in test week 2 , the vehicle-infused animals showed signifcant forgetting of the previously acquired performance compared to the vehicle-infused animals over the time interval of $12 \mathrm{~d}$ between test week 1 and $2(+, p<0.01$, Student's related $t$ test; $A$ ). Furthermore, between day 3 (visible platform) and day 4 (nonvisible platform), the vehicle-infused animals again showed significant forgetting compared to the NGF-treated animals $(+, p<0.05$, post hoc Student's related $t$ test; $A$ ). Thus, on day 4 the NGFtreated aged rats performed significantly better than the vehicle-infused aged animals $*^{*}, p<0.05$, Student's unrelated $t$ test). For the escape-latency parameter, the NGF-treated animals performed significantly better on all days in test week 2, except for day 3 (visible platform), than the vehicle-infused animals, which took more time to find the hidden platform than the NGF-infused animals, but found the visible platform equally fast as the NGF-infused animals. The swim speed of the vehicleinfused animals declined on the last 3 $\mathrm{d}$ in test week $2(p<0.05$ for test day $2 ; B)$ and this explains the reduced distance swum by these animals in test week 2 . This reduction in swim performance could be due to age-related motor impairments in combination with decreased somatic function in some of these animals.

1, and two were found to have abscesses in the right hemisphere on histological examination. The remaining seven vehicle-infused and six NGF-infused rats, together with the six nonimpaired aged rats and six young rats, were taken for morphometric analysis.

In the 30-month group, four vehicle- and five NGF-infused animals died during test week 2 . Of the seven vehicle-infused, six NGF-treated, and six young rats, four animals in each group showed sufficient histological quality for computerized image analysis. Statistical evaluation of cognitive performance included only those aged rats that were used in the morphometric analysis. 


\section{Platform crossings}

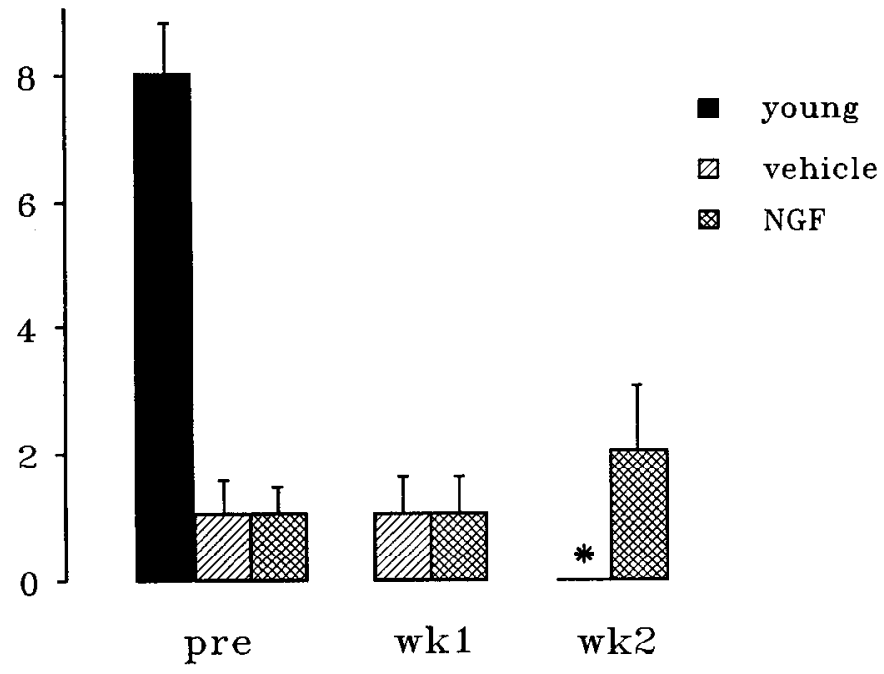

Figure 5. Thirty-month-old animals. As for the 18-month-old animals (Fig. 3), the spatial probe trial was located on the last day in the pretest and test week 1 , but on the first day of testing in test week 2 (see Fig. 1). On the last day in the pretest, the young animals showed good acquisition of the task and focused their search over the former platform site, whereas the aged animals had not learned the task as well as the young animals (mean \pm SEM). No difference could be observed between the vehicle- or NGF-infused animals in the pretest and test week 1 . In test week 2, none of the vehicle-infused animals swam over the former platform site, whereas the NGF-treated animals showed some focused search $\left(^{*}, p<0.05\right.$, Student's unrelated $t$ test).

\section{Behavior}

Eighteen-month group. During the period of continuous infusion, the NGF-infused $(n=6)$ and vehicle-infused $(n=7) \mathrm{im}-$ paired aged rats and the nonimpaired aged animals $(n=6)$ were retested twice in the Morris water maze (see above, Fig. 1). In the pretest, all animal groups showed learning of the task, as measured by reduction in escape latency and distance swum to the platform during the $5 \mathrm{~d}$ of testing ( $p<0.01$, two-way ANOVA; see Fig. 2). The nonimpaired aged animals performed significantly better than the two impaired groups $(p<0.01$, oneway ANOVA with post hoc Fisher PLSD for both latency and distance). The performance of the nonimpaired aged rats was similar to that of the animals in the young group in this test (Fig. 2, open squares). On the first day of test week 1, the NGFinfused and the nonimpaired (nonoperated) animals performed as well as they did on the last $2 \mathrm{~d}$ (days 4 and 5) in the pretest, whereas the vehicle-infused animals showed significant forgetting ( $p<0.05$, two-way ANOVA with post hoc Student's related $t$ test for both latency and distance), as measured by both the escape latency (Fig. $2 A$ ) and the distance swum before finding the hidden platform (Fig. $2 B$ ). Thus, on day 1 in test week 1 , the NGF-treated animals performed significantly better than the vehicle-infused animals ( $p<0.05$, one-way ANOVA with post hoc Fisher PLSD for both latency and distance) and were no longer significantly different in performance compared to the aged nonimpaired, nonoperated animals. Although the NGFinfused animals tended to perform better than the vehicle-infused ones also during days 2-5 of test week 1 , this difference did not reach significance. No significant differences between test weeks 1 and 2 (12-d interval for all groups) in either escape latency or the distance swum to the platform were observed in any of the groups (Fig. 2). Also, the introduction of a visible platform on day 3 in test week 2 did not have any clear effect. However, between day 3 (visible platform) and day 4 (nonvisible platform) in test week 2 , the vehicle-infused animals showed significant forgetting of the previously acquired performance ( $p$ $<0.05$, two-way ANOVA with post hoc Student's related $t$ test for both latency and distance; Fig. 2) compared to the NGFtreated and nonimpaired aged animals, whereas the NGF-treated and the nonimpaired aged animals performed as well on the fourth day as they did on the third day.

The swim speed did not differ between the three groups in the pretest $(2.3 \pm 0.1 \mathrm{dm} / \mathrm{sec}$ for the vehicle-treated, $2.5 \pm 0.1$ $\mathrm{dm} / \mathrm{sec}$ for the NGF-treated, and $2.4 \pm 0.1 \mathrm{dm} / \mathrm{sec}$ for the aged nonimpaired, nonoperated rats over the entire test week), and it did not differ from the swim speed recorded in the young animals $(2.7 \pm 0.2 \mathrm{dm} / \mathrm{sec})$. The aged rats maintained their swimming ability throughout the experiment. Thus, during test weeks 1 and 2, the recorded swim speeds did not significantly differ from the pretest in any of the test groups.

The spatial probe trial (see above) was performed on the last day in the pretest and in test weck 1 , but on the first day in test week 2 . In the pretest, the aged rats showed overall fewer platform crossings than the young group ( $p<0.05$, Student's unrelated $t$ test), but the nonimpaired and impaired rats did not significantly differ from each other. In test week 1 , the nonimpaired rats and the NGF-infused impaired rats tended to perform better than the vehicle-infused rats, but this difference did not reach significance (one-way ANOVA with post hoc Fisher PLSD; Fig. 3). However, on the first day of test week 2, both the NGF-infused, impaired aged rats and the nonimpaired aged animals performed significantly better than the vehicle-infused impaired group ( $p<0.05$, one-way ANOVA with post hoc Fisher PLSD; Fig. 3).

Thirty-month group. In the pretest, the two aged groups (later to receive either NGF or vehicle solution) reduced their escape latency over the five test days ( $p<0.05$, two-way ANOVA), but they performed much worse than the young control group (see Fig. 4). In test week 1, the NGF-infused animals did not differ in either escape latency or swim distance from the vehicleinfused rats, nor did they improve their performance relative to the pretest (two-way ANOVA). In test week 2, however, the mean performance of the NGF-infused rats was significantly better as a group compared to the vehicle-infused rats when measured as escape latency ( $p<0.01$, Student's unrelated $t$ test). This was due to a decline in the performance in the vehicleinfused group, while the performance of the NGF-infused rats remained stable between the two tests $(p<0.02$, two-way ANOVA; $G \times T, p<0.001)$. As is shown in Figure 4, the NGFinfused rats performed as well on the first day in the second test week as they did at the end of the previous test, whereas the vehicle-infused rats showed a significant retention deficit $(p<$ 0.01 , Student's related $t$ test). This difference was also evident on the sccond day in this test week. However, when introducing a visible platform to the water maze in test week 2 (day 3 ), the vehicle-infused aged animals did not perform significantly different from the NGF-treated animals. When the platform again was invisible to the animals (day 4 ), the vehicle-infused animals showed a significant retention deficit ( $p<0.05$, Student's related $t$ test) and performed significantly worse on the escape latency parameter compared to the NGF-infused animals $(p<0.01$, Student's unrelated $t$ test). 
MS

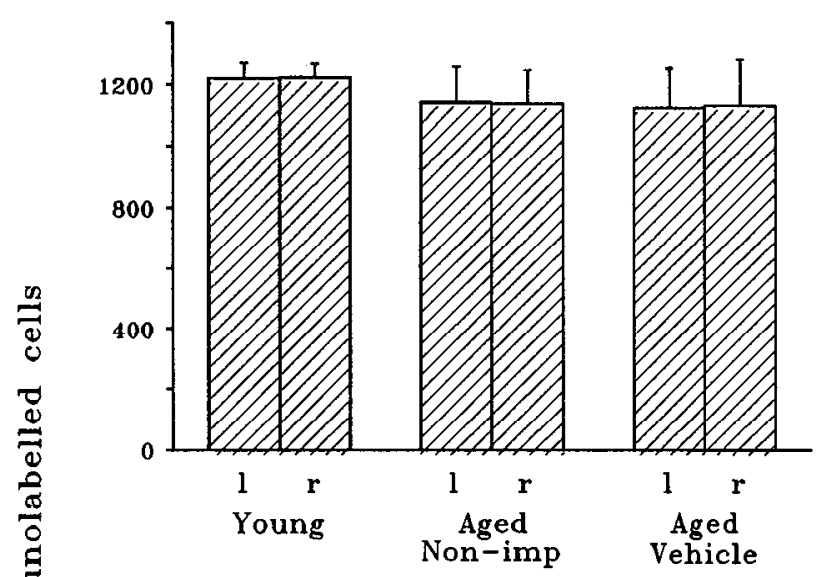

VDB

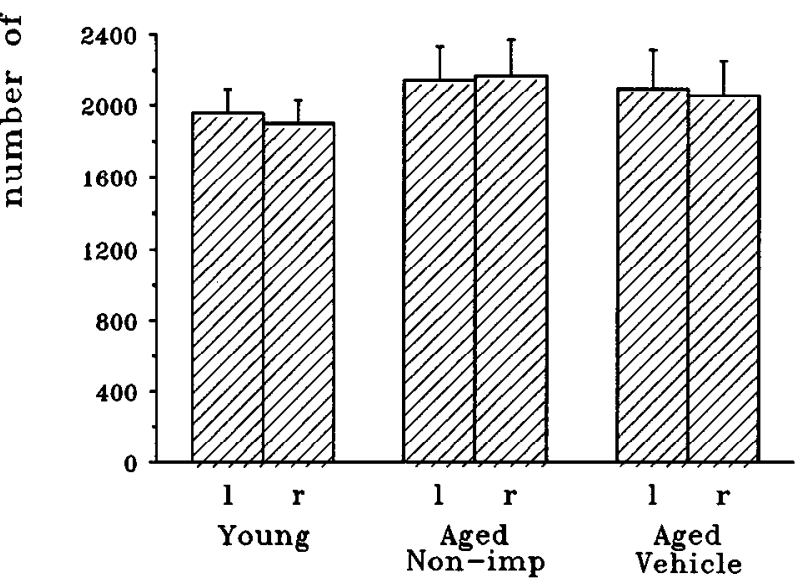

Striatum

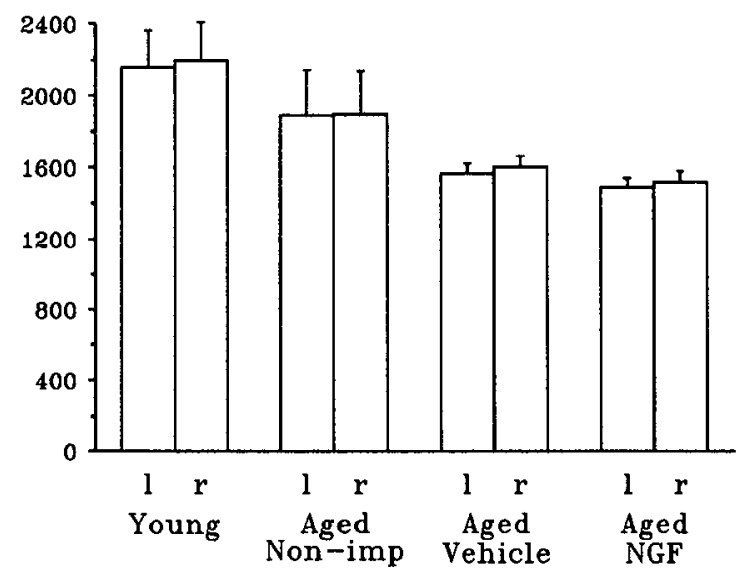

NBM

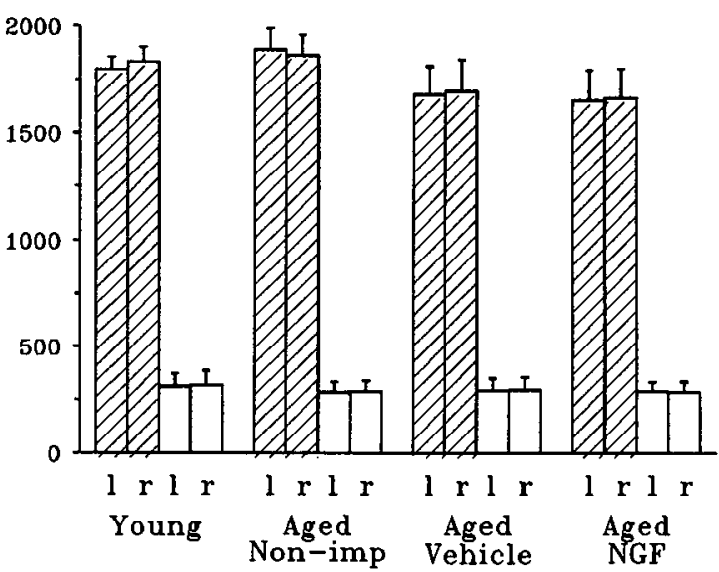

Figure 6. Eighteen-month group. Cell numbers of double-labeled neurons (NGFr + ChAT; hatched bars) in the $M S, V D B$, and $N B M$ on left $(l)$ and right $(r)$ sides in the 18-month-old animals and the parallel-processed young controls (mean + SEM). Single-labeled (ChAT) neurons in the striatum and $N B M$ are denoted by open bars. Note that measurements in $M S$ and VDB could not be performed in the NGF-treated animals due to high background of immunolabeling (NGFr $+\mathrm{ChAT}$ ) in this group. The cannula was located on the right $(r)$ side in the infused cognitively impaired aged animals. No differences in cell numbers could be detected between the animal groups.

None of the differences between the NGF- and vehicle-infused impaired rats, however, were seen on the distance parameter (see Fig. $4 B$ ). This discrepancy between the escape latency and distance measures was due to a progressive decline in swimming ability during the course of the expcriment in the 30 -monthold rats. In the pretest week, the aged rats had a swim speed of $2.4+0.2 \mathrm{dm} / \mathrm{sec}$, and the two aged groups did not differ from each other. During testing, the vehicle-infused aged rats, in particular, gradually decreased in their ability to swim. In test week 1 , the vehicle-infused animals swam $2.2 \pm 0.3 \mathrm{dm} / \mathrm{sec}$, and the NGF-infused rats, $2.5 \pm 0.2 \mathrm{dm} / \mathrm{sec}$; in test week 2 , the vehicleinfused animals swam $1.6 \pm 0.2 \mathrm{dm} / \mathrm{sec}$, and the NGF-infused rats, $2.2 \pm 0.2 \mathrm{dm} / \mathrm{sec}$. The reduced swimming ability was particularly evident on the last $3 \mathrm{~d}$ in test week 2 in the vehicleinfused group (possibly due to a combination of bad general condition of the animals and age-related motor impairments). Thus, on day 2 in test week 2 , the swim speed was $2.6 \pm 0.2$ $\mathrm{dm} / \mathrm{sec}$ (NGF-infused) and $1.7 \pm 0.1 \mathrm{dm} / \mathrm{sec}$ (vehicle-infused), on day 3 it was $2.2 \pm 0.2 \mathrm{dm} / \mathrm{sec}(\mathrm{NGF})$ and $1.6 \pm 0.1 \mathrm{dm} / \mathrm{sec}$ (vehicle), and on day 4 it was $2.0 \pm 0.1 \mathrm{dm} / \mathrm{sec}(\mathrm{NGF})$ and 1.4 $\pm 0.2 \mathrm{dm} / \mathrm{sec}$ (vehicle). Thesc differences, however, reached significance only on day 2 ( $p<0.05$, Student's unrelated $t$ test).
The spatial probe trials (Fig. 5) showed that none of the 30month-old rats had acquired any spatial memory of the platform site during the pretest. Thus, the 30 -month-old rats had, on average, one platform crossing as compared to a mean of eight for the young group. The spatial probe trial was repeated at the end of test week 1 (day 12 of continuous infusion). The number of platform crossings remained very low in both groups, and there was no significant difference between the vehicle- or NGFinfused animals (Fig. 5). On the first day of testing in test week 2 (day 25 of continuous infusion), after the eighth swim trial, the platform was again removed from the pool and the platform crossings counted. None of the vehicle-infused animals swam over the area where the former platform had been situated, whereas the NGF-infused rats showed some focused search over the platform site $(p<0.05$, Student's unrelated $t$ test; Fig. 5).

\section{Morphometry}

The mean number of cells measured on each side of each brain was about 2300 both in the young rats and in the 18-monthold noninfused, nonimpaired aged rats, about 2000 in the cognitively impaired 18-month-old animals, and about 1600 in the 30 -month-old animals. The values given in Figures 6 and 7 
MS

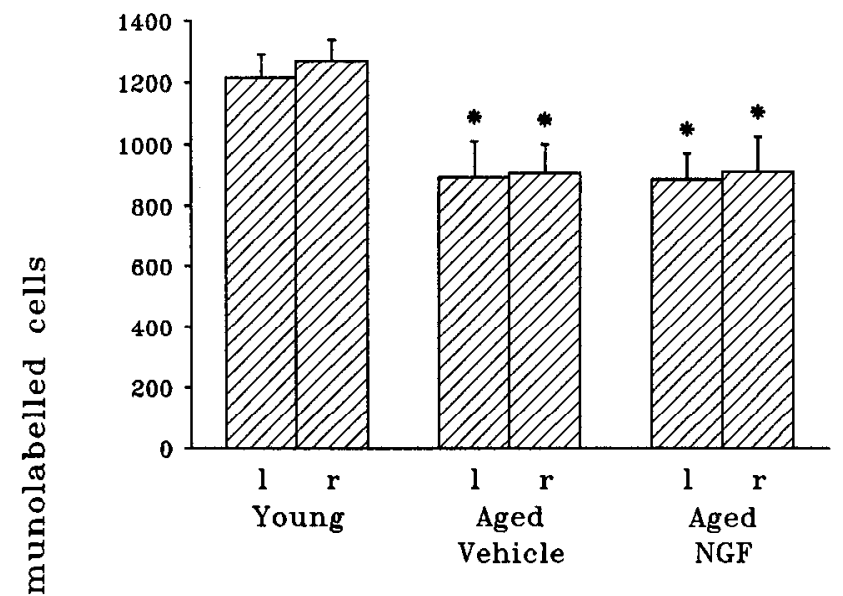

VDB

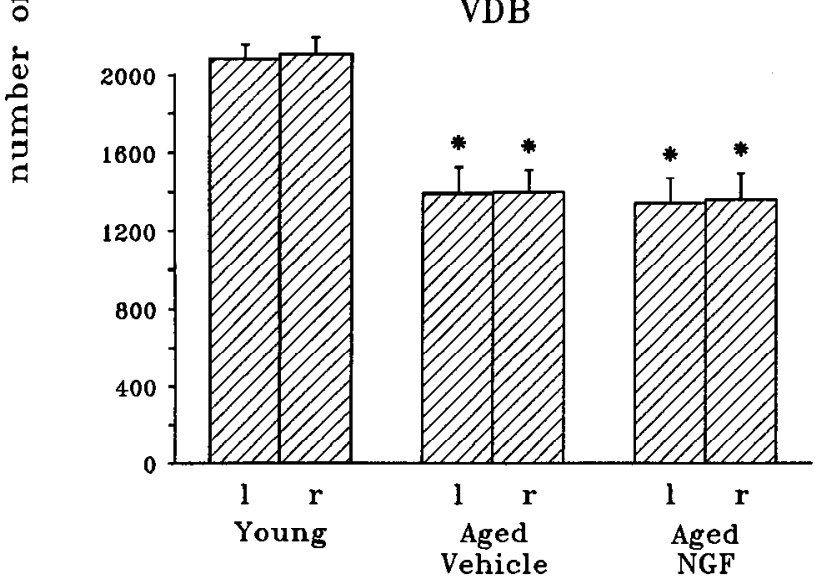

Striatum

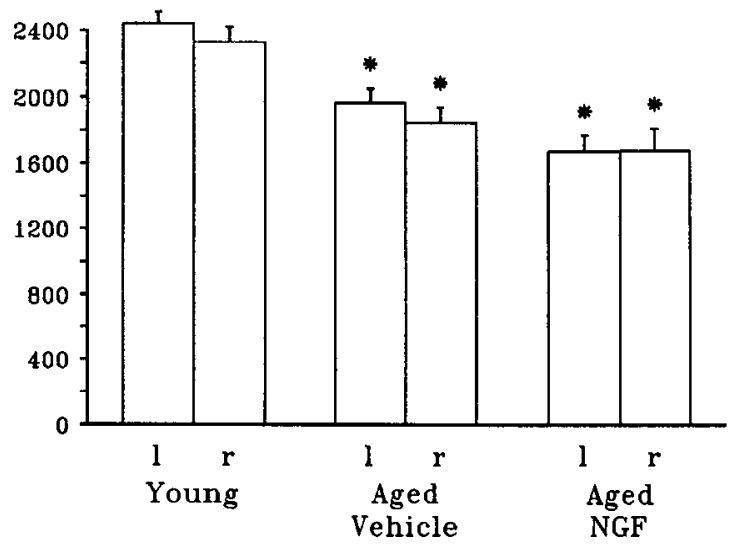

NBM

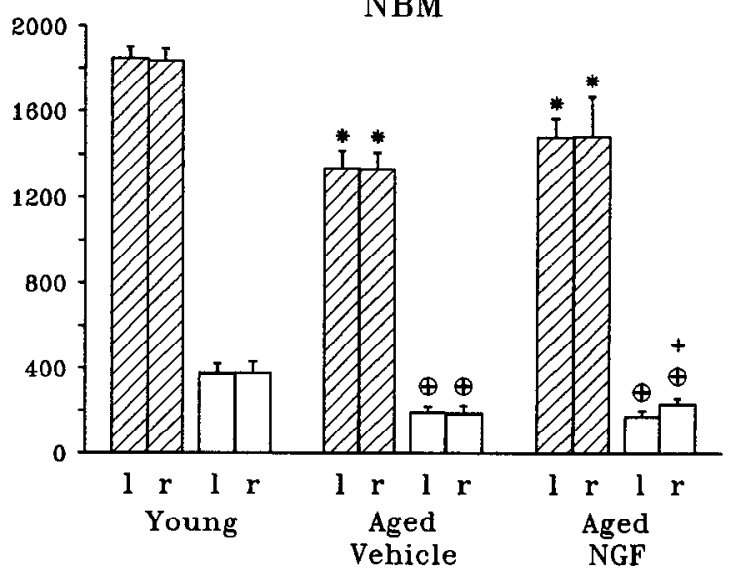

Figure 7. Thirty-month group. Cell numbers of double-labeled neurons (ChAT + NGFr; hatched bars) in the $M S, V D B$, and $N B M$ on left $(l)$ and right $(r)$ sides in the 30-month-old animals and the parallel-processed young controls. Single-labeled (ChAT) neurons in the striatum and $N M B$ are denoted by open bars. In the infused aged impaired animals, the infusion cannula was located on the right side. The bars provide means of corrected counts \pm SEM. MS: *, significant reduction (about $26 \%$ ) compared to the young group $(p<0.05$, one-way ANOVA with post hoc Fisher PLSD); $V D B:$ *, significant reduction (about $36 \%$ ) compared to the young group $(p<0.05$, one-way ANOVA with post hoc Fisher PLSD); Striatum: *, significant reduction (about 26\%) compared to young animals $(p<0.005$, one-way ANOVA with post hoc Fisher PLSD); NBM: *, significant reduction in numbers of double-labeled neurons (about $24 \%$ ) compared to the young group $(p<0.05$, one-way ANOVA with post hoc Fisher PLSD); + , significant reduction in numbers of single-labeled neurons (about 52\%) compared to the young animals $(p<0.001) ;+$, significant difference between left $(l)$ and right $(r)$ sides $(p<0.05$, Student's related $t$ test).

represent cell numbers corrected for split cell counts and section frequency according to Abercrombie (1946; see Materials and Methods). The young rats, which are referred to as the 3-month-old group throughout, were 3 months old at the start of the behavioral testing and 4 months old at the time they were killed for morphometric analysis.

All animals taken for morphological analysis had a clear cytoplasmic immunostaining for ChAT in neurons of the forebrain. In the MS (Figs. 8, 9) and the VDB (Figs. 10, 11), virtually all ChAT-positive neurons were also NGFr positive, and labeling for the NGFr was exclusively found on ChAT-labeled neurons. The striatal ChAT-positive neurons (Figs. 12,13) were not labeled for the NGFr [except in the most basal portion of the caudal part of the nucleus, where a few scattered doublelabeled (NGFr + ChAT) neurons could be observed]. In the NBM, on the other hand (Figs. 14, 15), about $70-80 \%$ of the ChAT-labeled neurons stained for NGFr in both the young and the aged animals. In the NGF-infused 18-month-old animals, morphometry could not be performed in the MS and VDB due to a high disturbing background staining around the infusion site in these animals.

\section{Eighteen-month group}

Cell number. No significant reductions in cell numbers were observed in the 18-month-old rats compared to the young animals (one-way ANOVA; Fig. 6). In the striatum there was a nonsignificant $(p<0.1)$ reduction of about $20 \%$ in the numbers of ChAT-positive neurons in the impaired aged animals compared to the young controls.

Cell size. No difference in cell size between the young and the 18-month-old rats was observed in any of the forebrain areas, MS, VDB, striatum, or NBM (Fig. 16). In the NGF-infused rats, the double-labeled neurons (NGFr + ChAT; Fig. 16, hatched columns) in the NBM were significantly larger on the side of the infusion (the right side) compared to the intact, noninfused side $(p<0.01$, Student's related $t$ test; Fig. 16). This difference 

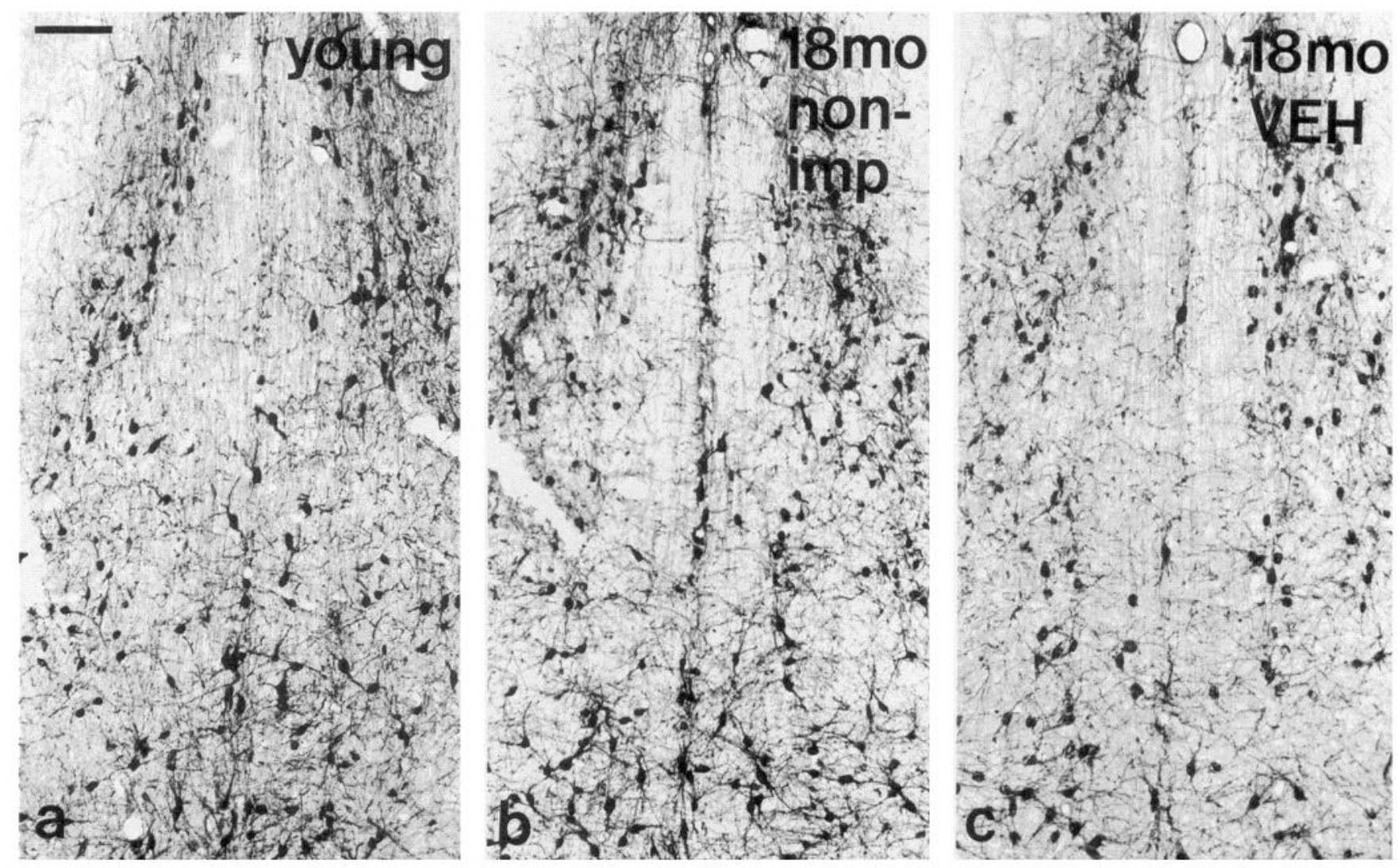

Figure 8. MS, 18-month group. Photomicrograph of NGFr+ChAT-positive neurons in a young (a), aged cognitively nonimpaired (non-imp; $b$ ), and vehicle-infused $(V E H)$ impaired $(c)$ animal. The NGF-treated rats all showed high background immunostaining (NGFr + ChAT) in this nucleus. Thus, in the NGF-treated group, this nucleus could not be included in the morphometric analysis. The cannula was located on the right side in the cognitively impaired aged animals. Scale bar, $100 \mu \mathrm{m}$.

was seen in all rats analyzed. Furthermore, the single-labeled neurons (ChAT only; Fig. 16, open columns) in the NBM were also increased in size on the NGF-infused side $(p<0.05$; Fig. 16). Also, the single-labeled neurons in the striatum were larger on the infused side compared to the contralateral side in all NGF-treated animals $(p<0.01)$. In the NGF-treated animals, the overall increase in cross-sectional area of the double-labeled (NGFr + ChAT) neurons in the NBM was about $20 \%$ compared to the contralateral side. The overall increase in cross-sectional area of the single-labeled (ChAT) cell bodies was $17 \%$ in the NBM and $30 \%$ in the striatum compared to the contralateral side.

\section{Thirty-month group}

Cell number. In the 30-month-old rats, the number of ChATand NGFr-positive cells was reduced compared to the young group in all four areas of the forebrain measured (left sides in Figs. 9, 11, 13, 15). The reduction in the number of immunolabeled neurons, as measured on the noninfused contralateral side, ranged from $24 \%$ to $52 \%$ (Fig. 7). The reduction in NGFr+ChAT-positive cells amounted to about $26 \%$ in the MS $(p<0.05$, one-way ANOVA with post hoc Fisher PLSD), 36\% in the VDB $(p<0.005)$, and $24 \%$ in the NBM $(p<0.05)$. The number of single-labeled neurons (ChAT-positive only) was reduced by about $26 \%$ in the striatum $(p<0.005)$ and $52 \%$ in NBM $(p<0.001)$. On the NGF-infused side, the only difference in cell number was seen in the single-labeled ChAT-positive neurons in the NBM, which were increased by $33 \%$ compared to the contralateral noninfused side (Fig. $7 ; p<0.05$, Student's related $t$ test).

Cell size. As illustrated in Figure 17, a reduction in size of immunolabeled neurons was observed in all areas except MS in the vehicle-infused 30-month-old animals and on the contralateral side of infusion in the NGF-treated animals, as compared to the young controls. The reduction in size of $\mathrm{NGFr}+\mathrm{ChAT}$-positive cells amounted to about $15 \%$ in VDB ( $p<0.05$, one-way ANOVA with post hoc Fisher PLSD), striatum $(p<0.001)$, and NBM $(p<0.05)$, whereas the size of the single-labeled ChAT-positive neurons in the NBM was reduced by about $30 \%$ compared to the young animals $(p<0.01)$.

In the NGF-infused rats, the double-labeled (NGFr + ChAT) neurons were significantly larger on the side ipsilateral to the infusion (the right side) compared to the noninfused side in the VDB $(p<0.05$, Student's related $t$ test; Fig. $11 c)$ and NBM ( $p$ $<0.01$; Fig. 15c). Furthermore, the single-labeled (ChAT) neurons in the striatum (Fig. 13c) and NBM (Fig. 15c) were also larger on the NGF-infused side compared to the contralateral side $(p<0.01$, Student's related $t$ test). The overall increase in cross-sectional area of double-labeled cells $(\mathrm{NGFr}+\mathrm{ChAT})$ was about $10 \%$ in the VDB, and in the NBM the double-labeled $(\mathrm{NGFr}+\mathrm{ChAT})$ and the single-labeled (ChAT) cell bodies were increased in size of about $25 \%$. In the single-labeled (ChAT) cell bodies of the striatum, the increase in size amounted to about $20 \%$ on the NGF-infused side. On the NGF-infused side, 

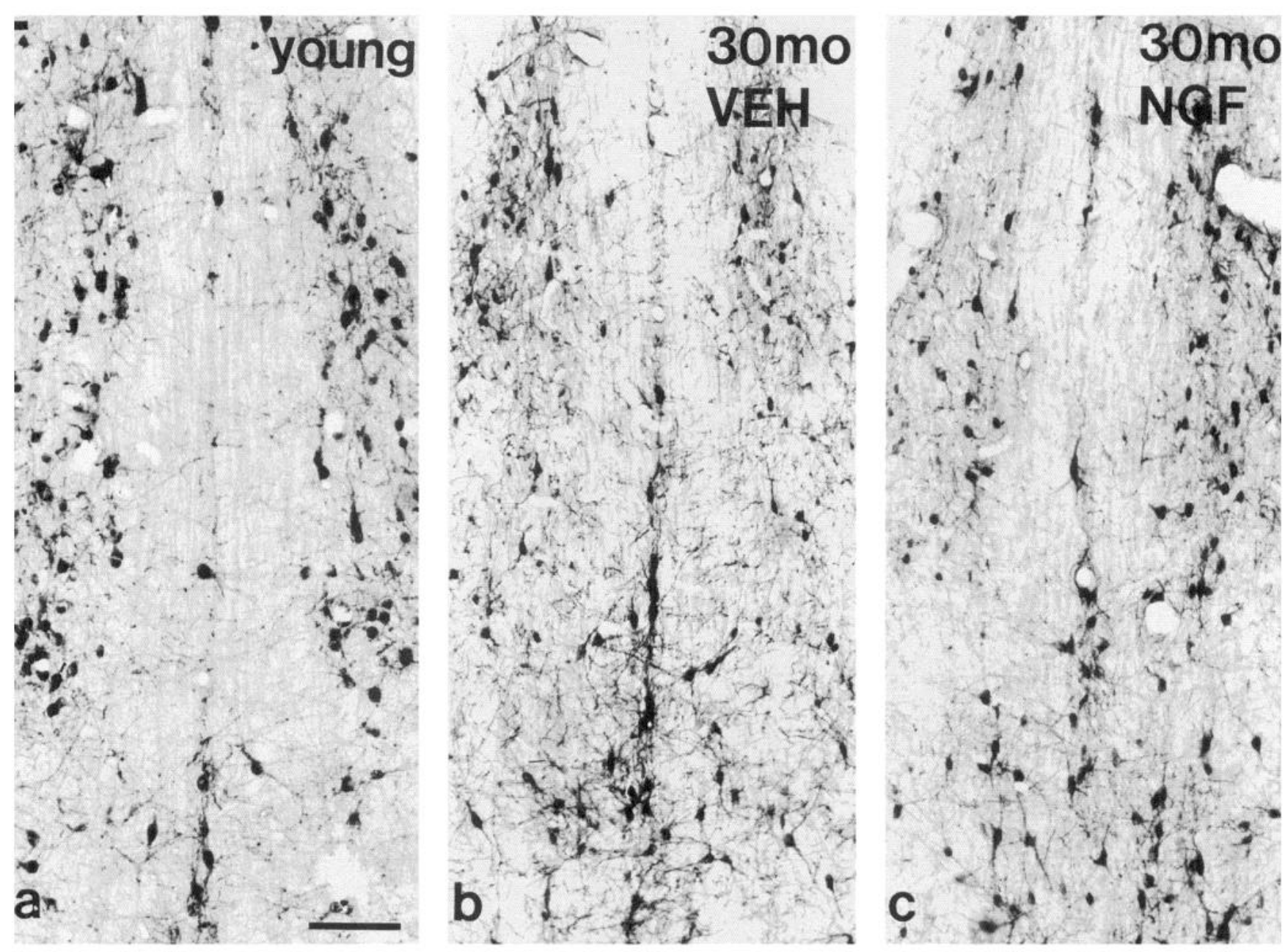

Figure 9. MS, 30-month group. Photomicrograph of double-labeled (NGFr + ChAT) neurons of a young (a), aged vehicle-treated $(V E H ; b)$, and aged NGF-treated $(c)$ animal. Note the loss of immunolabeled neurons in the aged animals. Adjacent to the infusion cannula (on the right side) in the MS of the NGF-treated animal (c), an apparent increase in cell size of neurons on the ipsilateral side to the NGF infusion (i.e., the right side) can be observed. Scale bar, $100 \mu \mathrm{m}$.

the size of the double-labeled neurons in the VDB and NBM and the single-labeled neurons in the striatum was not significantly different compared to the young rats (Fig. 17).

\section{Discussion}

The cholinergic neurons of the basal forebrain show morphological changes characteristic of degeneration with age. At present it is unclear to what extent NGF might be related to the events leading to such age-related degenerative changes in the cholinergic neurons. After axotomy, cholinergic neurons will degenerate and/or undergo severe atrophy, and this process can be counteracted by chronic intraventricular NGF infusions or implantation of NGF-producing cells (Hefti, 1986; Williams et al., 1986; Kromer, 1987; Gage et al., 1988; Montero and Hefti, 1988; Strömberg et al., 1990). The present results support our previous observation that chronic NGF infusions can increase the size of shrunken cholinergic neurons on the side of the infusion in aged rats. There was also improved retention of a spatial task that had been learned during or prior to the chronic NGF infusion. In our first study (Fischer et al., 1987), we used 24-month-old rats and $\mathrm{AChE}$ as a histological marker of cholinergic neurons. In the present study, we have extended our initial observations to 18 - and 30 -month-old rats, to determine the age limitations of the NGF effect. In this study, we also used ChAT and NGFr immunoreactivity as more accurate markers of cholinergic cells.

Behavioral characterization. The behavioral effect of intraventricular NGF infusion was most pronounced in the younger animals. Thus, in the 18-month group, the escape latency on test day 1 in the first test week was reduced by about half compared to the vehicle-infused animals, and in the 30-month-old NGF-infused animals (test day 1 in the second test week), by

Figure 11. VDB, 30-month group. Photomicrograph of double-labeled neurons (NGFr + ChAT) in a young (a), aged vehicle-treated ( VEH; $b$ ), and aged NGF-treated $(c)$ animal on the right side. Loss and cell atrophy of immunolabeled neurons is apparent in this nucleus in the aged animals. In the NGF-treated animals, a marked reduction in atrophy is evident on the side ipsilateral to the NGF infusion (i.e., the right side, $c$ ). Scale bar, $100 \mu \mathrm{m}$. 

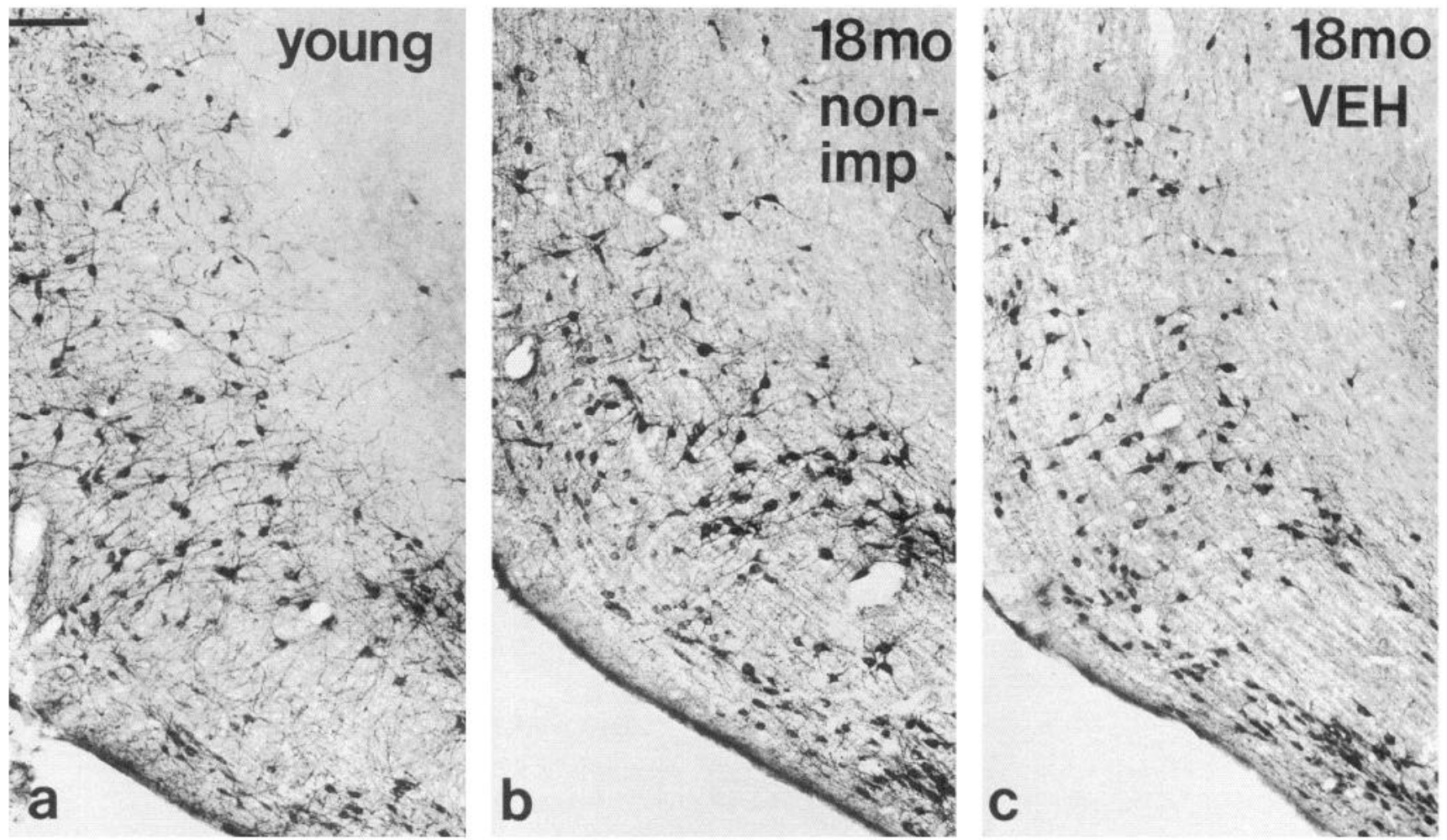

Figure 10. VDB, 18-month group. Photomicrograph of NGFr +ChAT-positive neurons in a young (a), aged cognitively nonimpaired (non-imp; $b$ ), and aged vehicle-infused $(V E H)$ impaired $(c)$ animal on the right side (i.e., the infused side in the aged impaired animals). Also in this nucleus, the NGF-treated animals showed high background immunostaining (NGFr + ChAT), and this nucleus was subsequently not included in the morphometric analysis. Scale bar, $100 \mu \mathrm{m}$.
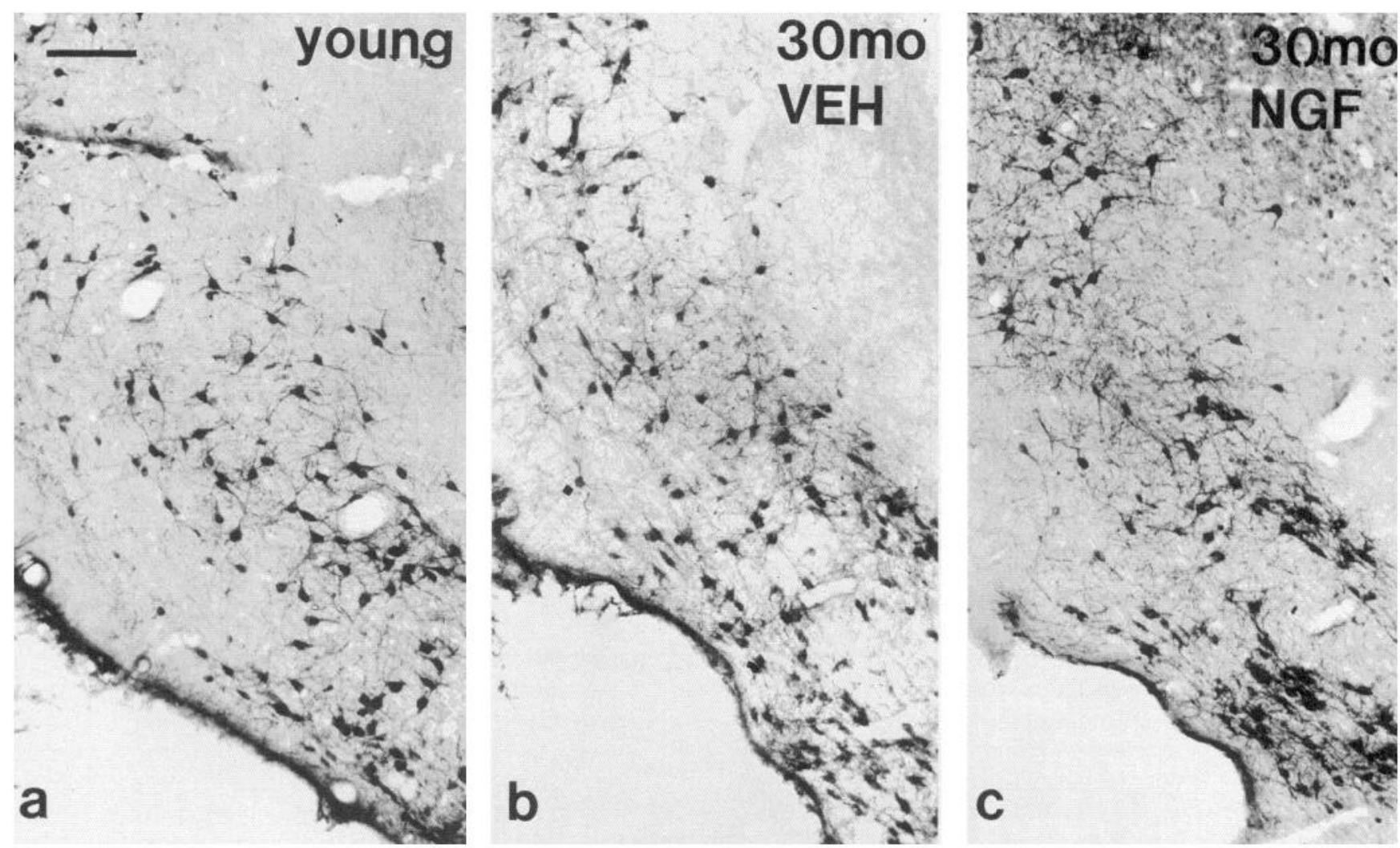

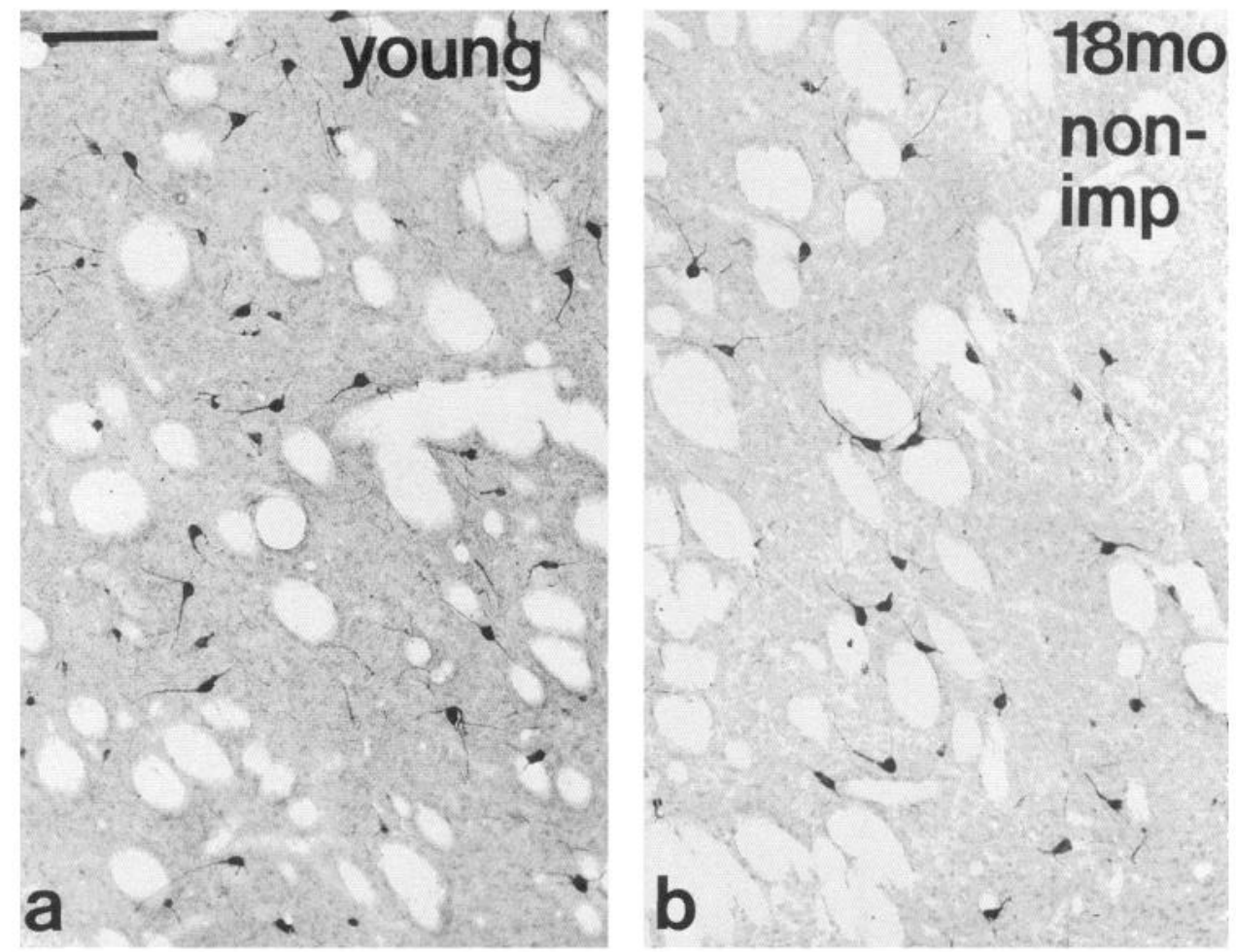

Figure 12. Striatum, 18-month group. Photomicrograph of ChAT-labeled neurons in a young $(a)$, aged cognitively nonimpaired (non-imp; $b$ ), vehicle-infused $(V E H)$ aged impaired $(c)$, and NGF-treated aged impaired $(d)$ animal on the right side. Note that the neurons in the NGF-treated animal are hypertrophied. The right side was infused in the cognitively impaired aged animals. Scale bar, $100 \mu \mathrm{m}$.
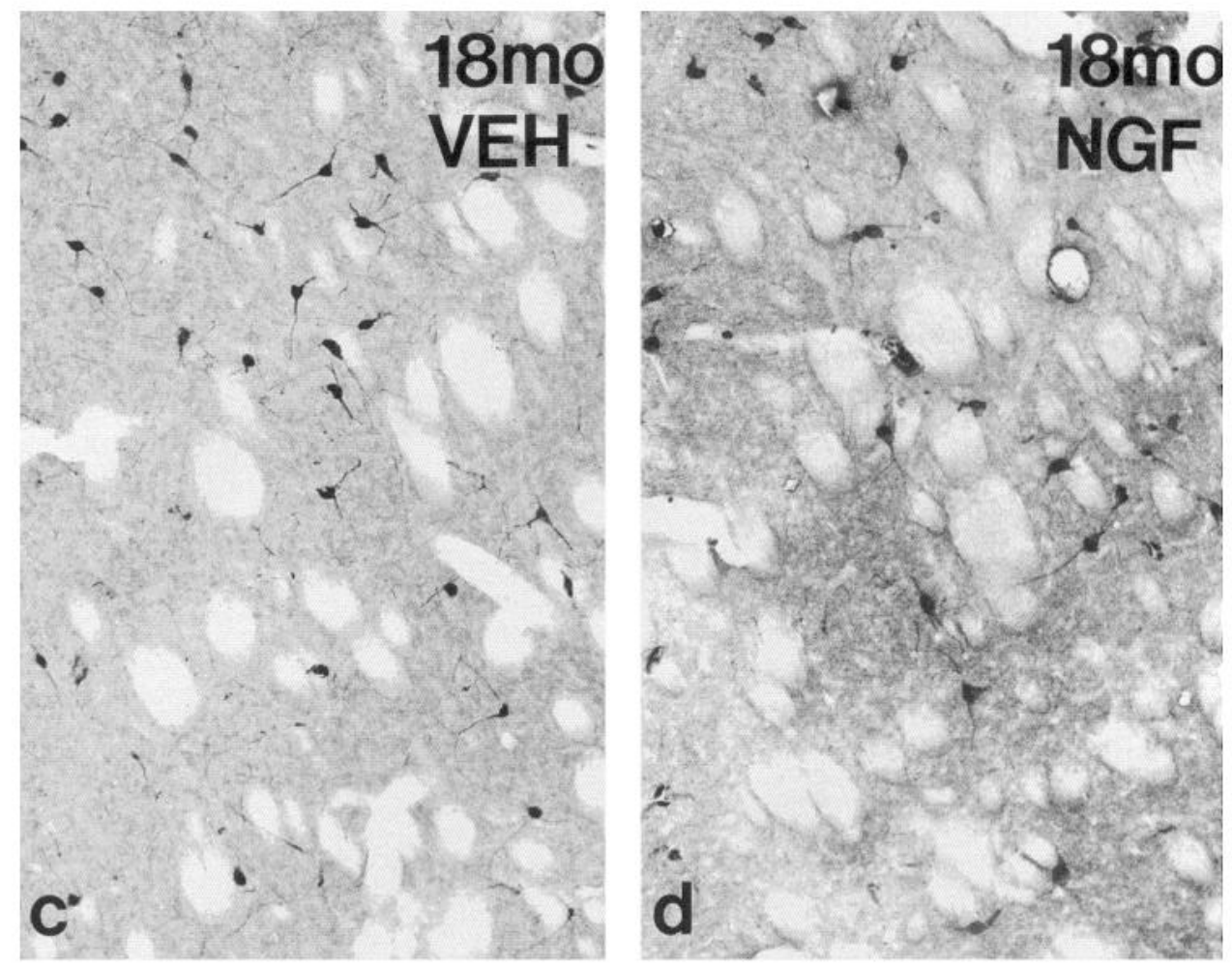

about $25 \%$ compared to the aged controls. Furthermore, the behavioral effect of NGF was already apparent after $8 \mathrm{~d}$ of continuous infusion in the 18-month-old animals, whereas any behavioral effect by NGF in the 30-month-old animals was seen only after $25 \mathrm{~d}$ of infusion. In both groups, the effect was seen on parameters of retention of previously acquired performance, and in none of the experiments was it possible to detect any effect of NGF on acquisition of place navigation in the water maze task. In the present study, the 18-month-old rats showed an improved performance in the beginning of the first test week, which suggests an improved retention of the performance they had acquired prior to NGF infusion. In contrast, the 30-monthold NGF-infused animals, like the 24-month-old NGF-infused animals in the previous study, did not perform differently from 

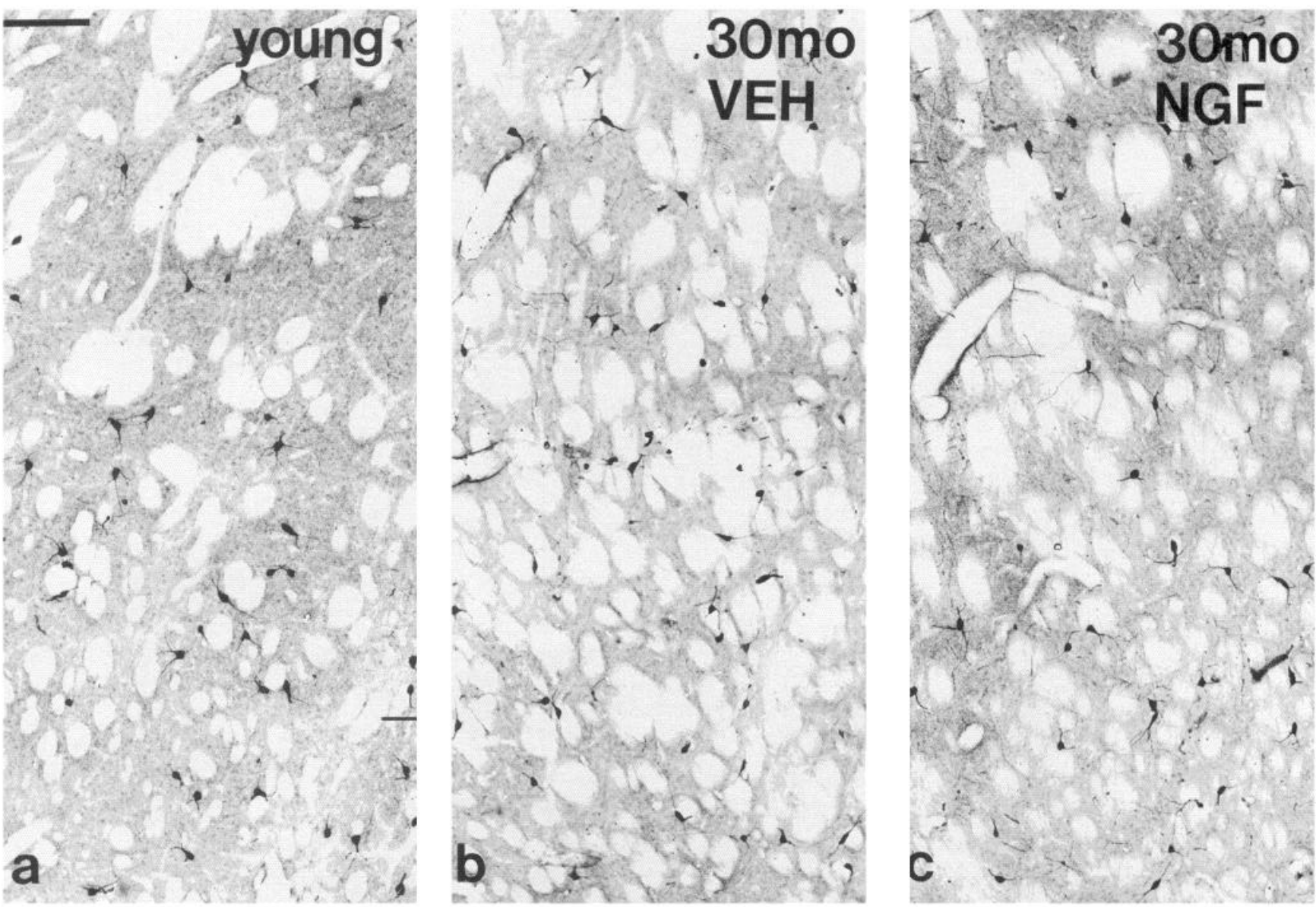

Figure 13. Striatum, 30-month group. Single-labeled (ChAT) neurons in a young (a), aged vehicle-treated $(V E H ; b)$, and aged NGF-treated (c) animal on the right side (i.e., the infused side in the aged animals). Loss of immunolabeled neurons as well as cell atrophy is evident in this nucleus in the aged animals. In the NGF-treated animal $(c)$, an increase in cell size is observed on the side ipsilateral (i.e., the right side) to the NGF infusion. Scale bar, $100 \mu \mathrm{m}$.

the vehicle-infused animals in test week 1 . Instead, the older animals showed improved retention over the interval between test weeks 1 and 2, during ongoing NGF infusion, when the performance of the vehicle-infused older rats showed a significant decline. While the performance of the vehicle-infused aged rats was significantly worse than that of the NGF-infused aged rats during test week 2 , this difference was only seen in the escape latency measure. This effect was primarily due to a reduced swim speed in the vehicle-infused impaired rats in test week 2 . However, because the difference between the vehicleand NGF-infused group disappeared when the escape platform was made visible (day 3 in test week 2), the discrepancy between the latency and distance measures did not seem to reflect impaired swimming ability in the vehicle-infused rats. NGF appeared to counteract the progressive performance deficit in the 30 -month-old rats. It is notable, however, that the NGF infusion had no clear-cut effect on the platform-crossings measure in the spatial probe trial, which makes it unlikely that the effects in the 30-month-old rats are related to improved spatial memory performance. This is in contrast to the 18-month-old animals, where this spatial memory parameter was significantly improved in the NGF-infused group.

Morphological characterization. With the double-labeling procedure for ChAT and NGFr immunoreactivity, we had the advantage of being able to characterize more accurately the affected neurons in the basal forebrain than with $\mathrm{AChE}$ staining as used in the previous experiment. The disadvantage was that, in order to make comparable analyses between groups and animals, we had to use rigid criteria for successful staining. These criteria lead to the exclusion of some animals from the analysis. The loss of the animals from morphological analysis did not affect the interpretation of the behavioral results, even though in the final behavioral analysis we only used those animals that qualified for morphological analysis.

Although in the 18-month-old group we did not detect any significant decrease in either cell number or cell size compared to the young controls, the NGF infusion produced an increase in size of the single- and double-labeled neurons on the side of the infusion. In contrast, the 30-month-old aged impaired group showed significant decreases in both cell size and cell number, and the reduction in cell size was partially or completely reversed by the chronic NGF infusion. Although the NGF infusion had no effect on the numbers of immunoreactive cell bodies, it is interesting to note that an increase in the number of singlelabeled ChAT-positive neurons was measured in the NBM after NGF infusion. This suggests that some of the cholinergic neurons may have lost ChAT expression and, following NGF infusion, increased their ChAT expression to detectable levels. It 

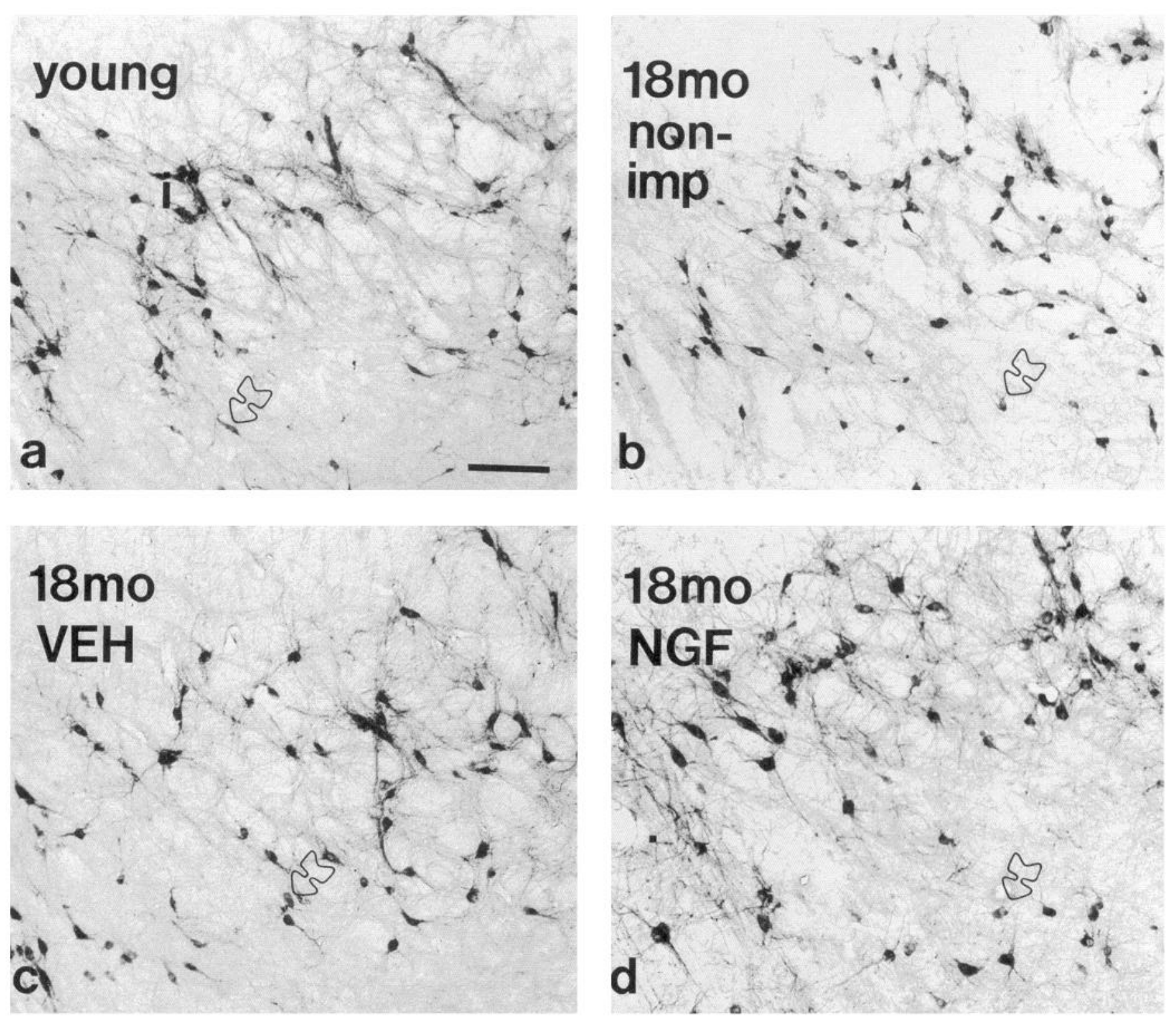

Figure 14. NBM, 18-month group. Photomicrograph of double-labeled (NGFr + ChAT) and single-labeled (ChAT; open arrows) neurons in a young $(a)$, cognitively nonimpaired (non-imp; $b$ ), vehicle-infused $(V E H)$ aged impaired $(c)$, and NGF-treated aged impaired $(d)$ animal on the right side (i.e., infused side in the cognitively impaired aged animals). The double-labeled neurons (NGFr $+\mathrm{ChAT}$ ) appear as black cell bodies, whereas the single-labeled (ChAT) neurons display a gray color (open arrows). Note the hypertrophy of both double- (NGFr + ChAT) and single-labeled (ChAT) neurons in the NGF-treated animal. Scale bar, $100 \mu \mathrm{m}$.

should be noted, however, because the number of ChAT-positive, NGFr-negative neurons in the NBM is low, that this effect was quite small in terms of number of stained cells.

As in our previous study, NGF induced an increase in cell size in the ChAT-immunoreactive striatal neurons in both age groups. These cells did not stain for NGFr in either the controls or the NGF-infused rats. The striatal cholinergic neurons are known to respond to NGF (Mobley et al., 1985; Fischer et al., 1987; Gage et al., 1989; Hagg et al., 1989); we interpret this finding to mean that the NGFr levels of these cells are below the level of detection in the immunohistochemical procedure.

Several observations suggest that the effect of NGF on the basal forebrain cholinergic neurons may be viewed as a pharmacological action of the factor on the aging brain, rather than a substitution of an age-dependent NGF deficit. First, the ob- servations in the 18-month-old rats indicate that marked behavioral deficits appear prior to the development of any notable atrophy or cell loss in the cholinergic system. Second, though there is a report of a $40 \%$ decrease in hippocampal NGF levels in aged Fischer 344 rats (Lärkfors et al., 1987a,b), we have in a parallel study (Hellweg et al., 1990) failed to detect any decrease in NGF levels in hippocampus or other brain regions in the rat strain (Sprague-Dawley) used here. Similar results have been obtained by Otten et al. (1989) in aged Fu and Wistar rats. Thus, reduced brain NGF levels do not seem to be a consistent finding in behaviorally impaired aged rats. Interestingly, the NGF (revealed by the 192-IgG monoclonal antibody) has been reported to be reduced in the basal forebrain of aged rats (Koh and Loy, 1988; Gomez-Pinilla et al., 1989; Markram and Segal, 1990) as well as in the hippocampus (Angelucci et al., 1988). 

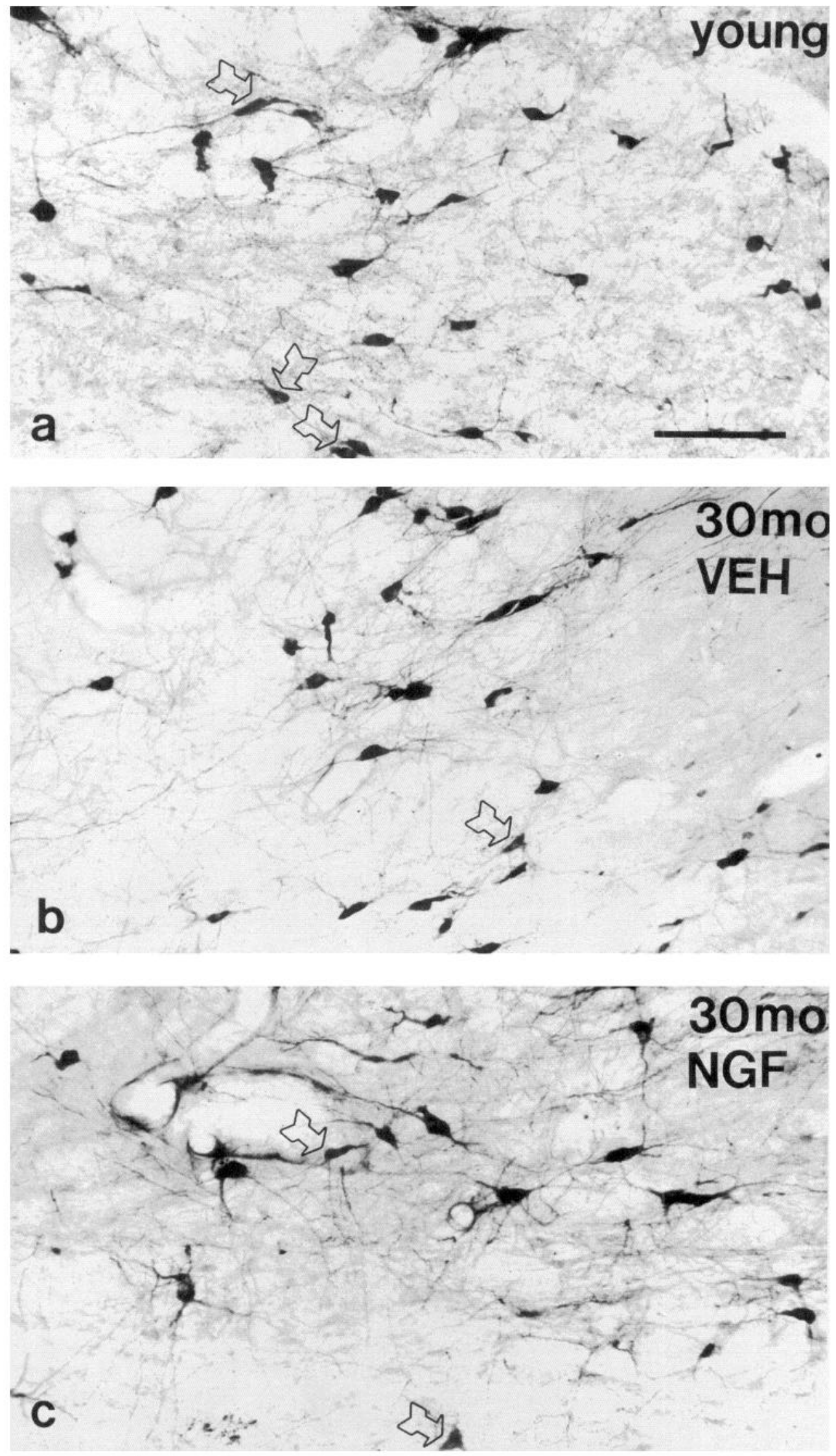

Figure 15. NBM, 30-month group. Single- as well as double-labeled neurons in a young $(a)$, aged vehicle-treated $(V E H ; b)$, and aged NGF-treated $(c)$ animal. The double-labeled neurons (NGFr + ChAT) appear as black cell bodies, whereas the single-labeled neurons (ChAT) display a gray color (open arrows). In the aged animals, atrophy is evident, as well as loss of immunolabeled neurons. On the NGF-treated (right) side, a marked increase in cell size is apparent in both the double- and the single-labeled cell population. Scale bar, $100 \mu \mathrm{m}$. 
MS

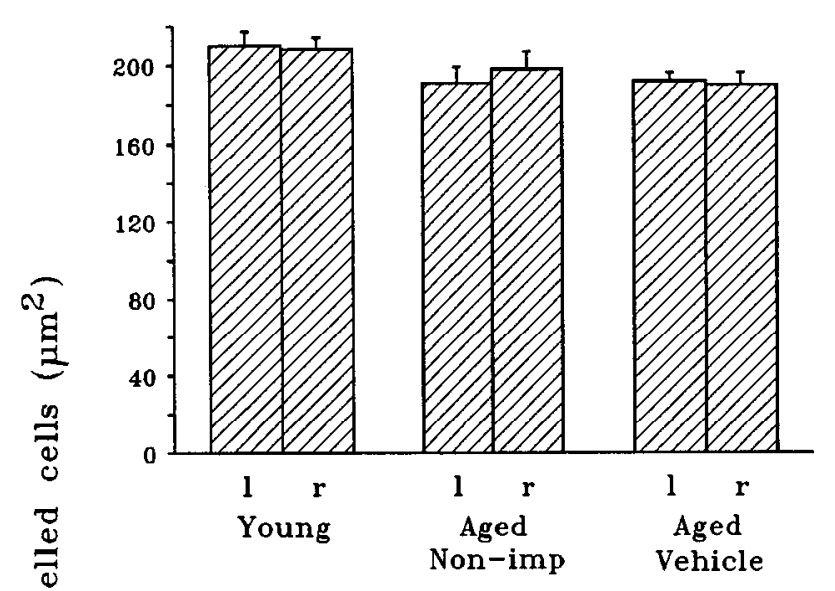

VDB

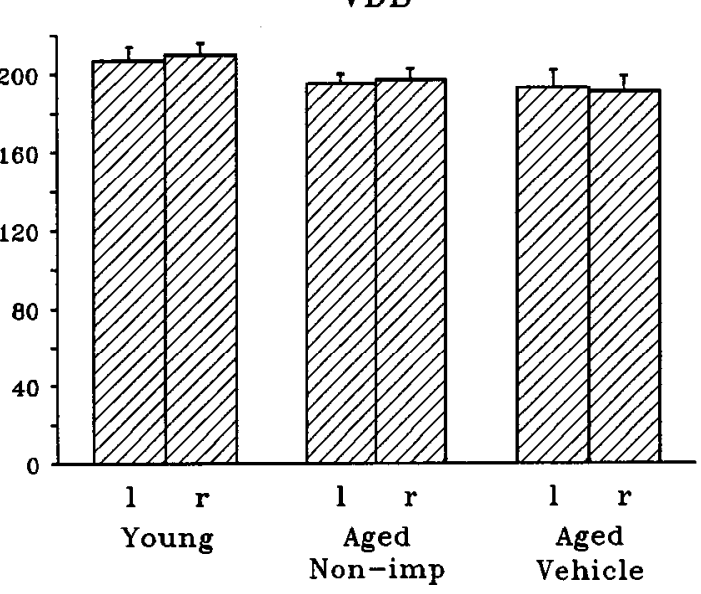

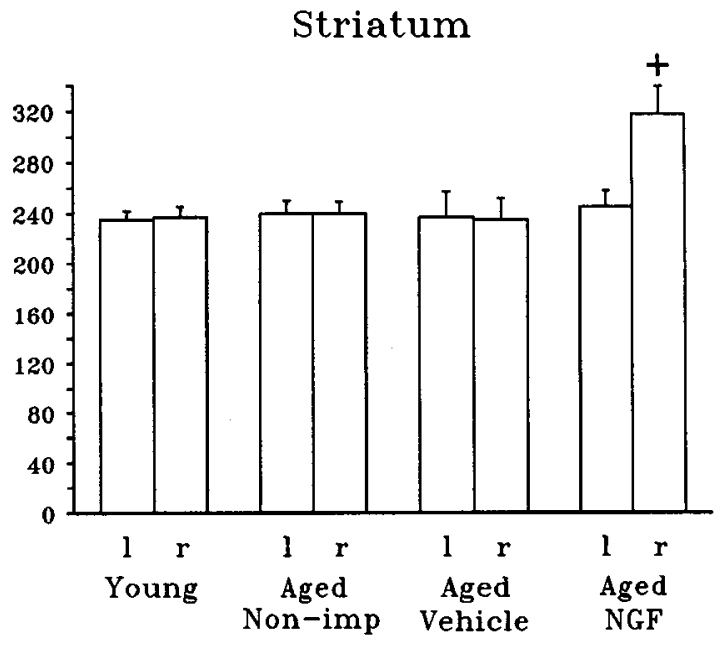

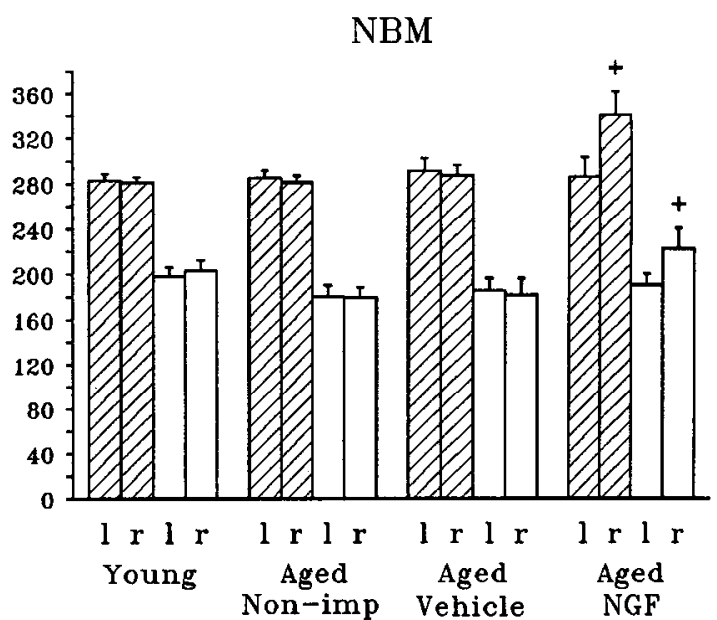

Figure 16. Eighteen-month group. Cell size of double-labeled neurons (NGFr + ChAT; hatched bars) in the $M S, V D B$, and NBM, on left ( $l$ ) and right $(r)$ sides (mean \pm SEM). Single-labeled (ChAT) neurons in the striatum and $N B M$ are denoted by open bars. Because of high background (NGFr + ChAT) in the NGF-treated animals in the $M S$ and $V D B$, no measurements could subsequently be performed in this group. The cannula was located on the right $(r)$ side in the infused cognitively impaired aged animals. In the striatum, a hypertrophy in size of single-labeled (ChAT) cell bodies compared to the contralateral side of about $30 \%$ was apparent in the NGF-treated animals on the side of infusion (i.e., the right side; $p<0.01$, Student's related $t$ test). In the $N B M$, the double-labeled neuronal population was also hypertrophied on the NGF-infused ( $r$ ) side in the NGF-treated animals $(+20 \%)$ compared to the contralateral side $(p<0.01$, Student's related $t$ test). Furthermore, the single-labeled (ChAT) neurons were also hypertrophied on the NGF-treated side $(+17 \%)$ compared to the contralateral side $(p<0.05)$.

Nevertheless, the present findings indicate that the forebrain cholinergic neurons remain responsive to exogenous NGF at advanced age.

NGF infusions have been discussed as a potential therapy for some components of the cognitive impairments associated with Alzheimer's disease (AD). Although aged rats do not show any of the specific neuropathological changes associated with AD, they can serve as a useful model for age-related neurological and behavioral changes. From the results presented in this article, one may suggest that young rather than old individuals may be most responsive to exogenously administered NGF. Significant questions remain, however, concerning the biological significance of the effects of exogenous NGF on age-related spatial memory dysfunction in the rat. The observed effects are clearly partial and limited to some aspects of memory retention in the place navigation test. It will be important, therefore, to determine whether grcatcr access to NGF by the affected neurons will result in more complete restoration of cognitive function and whether other aspects of impaircd lcarning, for example, memory acquisition, will be possible to influence through administration of trophic factors. In this regard it seems clear that, as the animals age (to 30 months), additional age-related impairments in performance complicate the interpretation of the findings.

Conclusions. The results indicate that (1) chronic infusions of NGF can influence age-related decline in parameters of spatial memory retention, but not acquisition, in the water maze task; (2) the effects of NGF on spatial memory performance in the aged rat may be mediated at least in part via an effect on the cholinergic/NGFr-positive neurons of the basal forebrain; (3) the morphological response to exogenous NGF is not exclusively confined to older animals where shrinkage of the forebrain cholinergic neurons has become evident, but is seen also in younger impaired aged rats where measurable cholinergic cellular atrophy not yet has evolved; and (4) the behavioral effect of NGF is more pronounced in younger impaired aged animals (18 
MS

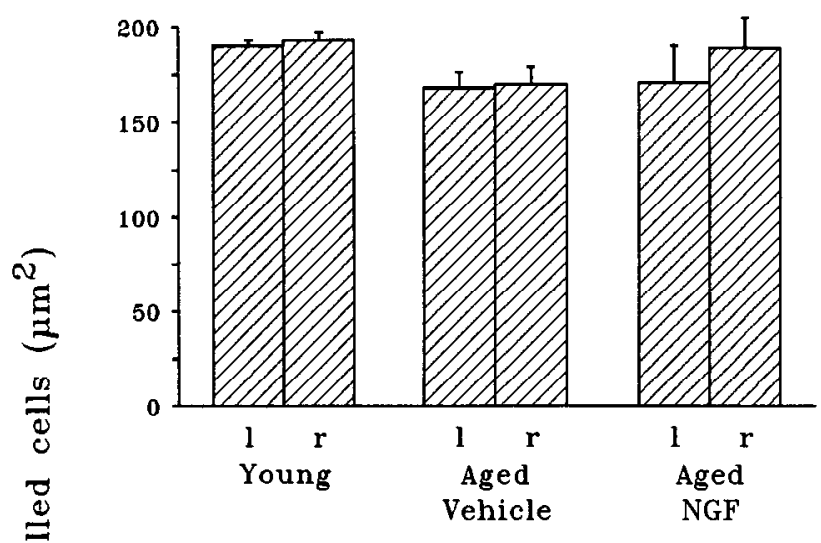

VDB

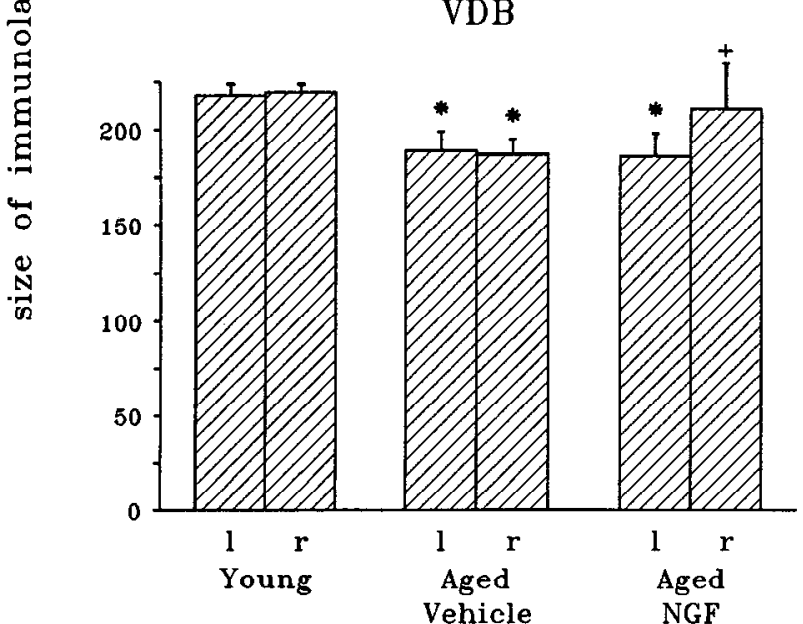

Striatum
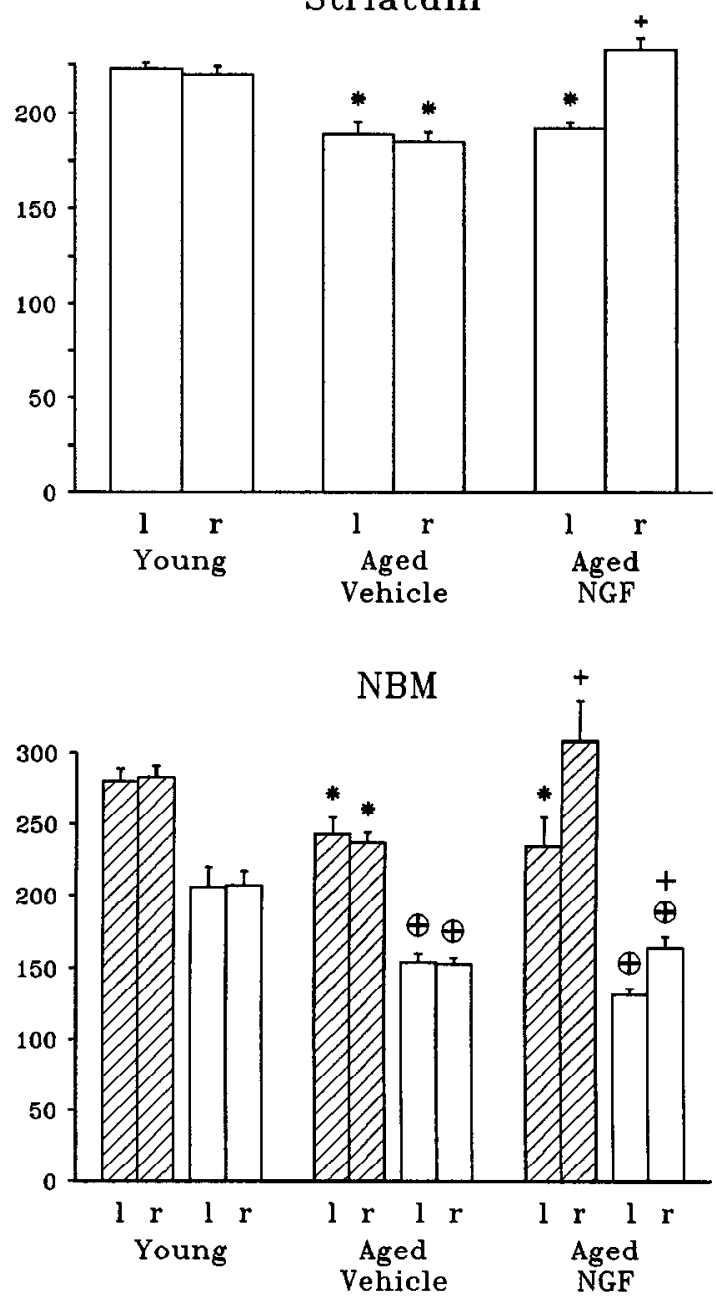

Figure 17. Thirty-month group. Sizes of double-labeled (NGFr + ChAT; hatched bars) neurons in the $M S, V D B$, and $N B M$ in the 30-month-old animals and the parallel-processed young controls, expressed as cross-sectional area in $\mu \mathrm{m}^{2} \pm$ SEM. Measurements were made both in left $(l)$ and right $(r)$ hemispheres, where the right hemisphere was infused in the aged impaired rats with either vehicle or NGF. VDB: *, significant reduction in size (about $15 \%$ ) compared to the young group ( $p<0.05$, one-way ANOVA with post hoc Fisher PLSD); + , significant difference (about $10 \%$ ) between left $(l)$ and right $(r)$ sides $\left(p<0.05\right.$, Student's related $t$ test); Striatum: ${ }^{*}$, significant reduction in size (about $\left.15 \%\right)$ compared to the young group $(p<0.001$, ANOVA post hoc Fisher PLSD); + , significant difference (about $+20 \%)$ between left $(l)$ and right $(r)$ sides $(p<0.001$, Student's related $t$ test); $N B M:{ }^{*}$, significant reduction in size of double-labeled neurons (about $15 \%$ ) compared to the young group ( $p<0.05$, one-way ANOVA with post hoc Fisher PLSD); + , significant reduction (about 30\%) in sizes of single-labeled neurons compared to the young group ( $p<$ 0.001 , one-way ANOVA with post hoc Fisher PLSD); + , significant difference (about $+25 \%)$ between sides $(p<0.01$, Student's related $t$ test).

months old) than in the older impaired ones ( 24 and 30 months old), though the interpretation of the behavioral changes in the oldest rats is confounded by the motor deficits seen in these severely impaired animals.

\section{References}

Abercrombie U (1946) Estimation of nuclear populations from microtome sections. Anat Rec 94:239-247.

Altavista MC, Bentivoglio AR, Crociani P, Rossi P, Albanese A (1988) Age-dependent loss of cholinergic neurons in the basal ganglia of rats. Brain Res 455:177-181.

Angelucci L, Ramachi MT, Taglialatela G, Hulsebosch C, Morgan B, Werrbach-Perez K, Perez-Polo R (1988) Nerve growth factor binding in aged rat central nervous system: effect of acetyl-L-carnitine. J Neurosci Res 20:491-496.

Ayer Lelievre CS, Ebendal T, Olson L, Seiger $\AA$ (1983) Localization of NGF-like immunoreactivity in rat neuron tissue. Med Biol 61: 296-304.

Batchelor PE, Armstrong DM, Blaker SN, Gagc FH (1989) Nerve growth factor receptor and choline acetyltransferase colocalization in neurons within the rat forebrain: response to fimbria-fornix transection. J Comp Neurol 284:187-204.

Biegon A, Greenberger V, Segal M (1986) Quantitative histochemistry of brain acetylcholinesterase and learning rate in the aged rat. Neurobiol Aging 7:215-217.

Collins F, Crutcher KA (1985) Neurotrophic activity in the adult rat hippocampal formation: regional distribution and incrcase after septal lesion. J Neurosci 5:2809-2814.

Fischer W, Wictorin K, Björklund A, Williams LR, Varon S, Gage FH (1987) Amelioration of cholinergic neuron atrophy and spatial memory impairment in aged rats by nerve growth factor. Nature 329:6568.

Fischer W, Gage FH, Björklund A (1989) Degenerative changes in forebrain cholinergic nuclei correlate with cognitive impairments in aged rats. Eur J Neurosci 1:34-45.

Gage FH, Björklund A (1986) Cholinergic septal grafts into the hippocampal formation improve spatial learning and memory in aged rats by an atropine-sensitive mechanism. J Neurosci 6:2837-2847.

Gage FH, Armstrong DM, Williams LR, Varon S (1988) Morphologic response of axotomized septal neurons to nerve growth factor. J Comp Ncurol 269:147-155.

Gage FH, Batchelor P, Chen KS, Chin D, Higgins GA, Koh S, Deputy 
S, Rosenberg MB, Fischer W, Björklund A (1989) NGF receptor reexpression and NGF mediated cholinergic neuronal hypertrophy in the damaged adult neostriatum. Neuron 2:1177-1184.

Gilad GM, Rabey JM, Tizabi Y, Gilad VH (1987) Age-dependent loss and compensatory changes of septohippocampal cholinergic neurons in two rat strains differing in longevity and response to stress. Brain Res 436:311-322.

Gomez-Pinilla F, Cotman CW, Nieto-Sampedro M (1989) NGF receptor immunoreactivity in aged rat brain. Brain Res 479:255-262.

Hagg TF, Hagg HF, Vahlsing M, Manthorpe M, Varon S (1989) Nerve growth factor effects on cholinergic neurons of neostriatum and nucleus accumbens in the adult rat. Neuroscience 30:95-103.

Hefti $F$ (1986) Nerve growth factor promotes survival of septal cholinergic neurons after fimbrial transections. J Neurosci 6:2155-2162.

Hefti F, Dravid A, Hartikka JJ (1984) Chronic intraventricular injections of nerve growth factor elevate hippocampal choline acetyltransferase activity in adult rats with partial septohippocampal lesions. Brain Res 293:305-311.

Hellweg R, Fischer W, Hock C, Gage FH, Björklund A, Thoenen H (1990) Nerve growth factor levels and choline acetyltransferase activity in the brain of aged rats with spatial memory impairments. Brain Res 537:123-130.

Hornberger J, Buell SJ, Flood DG, McNeill TH, Coleman PD (1985) Stability of numbers but not size of mouse forebrain neurons to 53 months. Neurobiol Aging 6:269-275.

Koh S, Loy R (1988) Age-related loss of nerve growth factor sensitivity in rat basal forebrain neurons. Brain Res 440:396-401.

Korsching S, Auburger G, Heumann R, Scott J, Thoenen H (1985) Levels of nerve growth factor and its mRNA in the central nervous system of the rat correlate with cholinergic innervation. Eur Mol Biol Org J 4:1389-1393.

Kromer LF (1987) Nerve growth factor treatment after brain injury prevents neuronal death. Science 235:214-216.

Large TH, Bodary SC, Clegg DO, Weskamp G, Otten U, Reichardt LF (1986) Nerve growth factor gene expression in the developing rat brain. Science 234:352-355.

Lärkfors L, Ebendal T, Whittemore SR, Persson H, Hoffer B, Olson L (1987a) Decreased level of nerve growth factor (NGF) and its messenger RNA in the aged rat brain. Mol Brain Res 3:55-60.

Lärkfors L, Ebendal T, Whittemore SR, Persson H, Hoffer B, Olson L (1987b) Developmental appearance of nerve growth factor in the rat brain: significant deficits in the aged forebrain. Prog Brain Res 78: 27-31.

Luine VN, Renner KJ, Heady S, Jones KJ (1986) Age and sex-dependent decreases in ChAT in basal forebrain nuclei. Neurobiol Aging 7:193-198.

Markram H, Segal M (1990) Regional changes in NGF receptor immunohistochemical labeling in the septum of the aged rat. Neurobiol Aging 11:481-484.

Mobley WC, Rutkowski JL, Tennekoon GIL, Gemski J, Buchanan
K, Johnston MW (1985) Choline acetyltransferase activity in striatum of neonatal rats increased by nerve growth factor. Science 229: 284-287.

Montero CN, Hefti F (1988) Rescue of lesioned septal cholinergic neurons by nerve growth factor: specificity and requirement for chronic treatment. J Neurosci 8:2986-2999.

Morris RGM (1981) Spatial localization does not require the presence of local cues. Learn Motiv 12:239-260.

Otten U, Lorez HP, Kettler R, Keller HH, Gallati H (1989) Agerelated changes in nerve growth factor, neurotransmitters and monoamine oxidase-B in rat brain. Klin Pharmakol 2:176-177.

Pioro EP, Cuello AC (1990) Distribution of nerve growth factor receptor-like immunoreactivity in the adult rat central nervous system. Effect of colchicine and correlation with the cholinergic system-I. Forebrain. Neuroscience 34:57-87.

Richardson PM, Verge Issa VMK, Riopelle RJ (1986) Distribution of neuronal receptors for nerve growth factor in the rat. J Neurosci 6:2312-2321.

Scott SM, Tarris R, Eveleth D, Mansfield H, Weichsel ME, Fisher DA (1981) Bioassay detection of mouse nerve growth factor (mNGF) in the brain of adult mice. J Neurosci Res 6:653-658.

Shelton DL, Reichardt LF (1986) Studies on the expression of the $\beta$-nerve growth factor (NGF) gene in the central nervous system: level and regional distribution of NGF mRNA suggest that NGF functions as a trophic factor for several distinct populations of neurons. Proc Natl Acad Sci USA 83:2714-2718.

Springer JE, Koh S, Tayrien MW, Loy R (1987) Basal forebrain magnocellular neurons stain for nerve growth factor receptor: correlation with cholinergic cell bodies and effects of axotomy. J Neurosci Res 17:111-118.

Strömberg I, Wetmore C, Ebendal T, Ernfors P, Persson H, Olson L (1990) Rescue of basal forebrain cholinergic neurons after implantation of genetically modified cells producing recombinant NGF. $J$ Neurosci Res 25:405-411.

Taniuchi M, Johnson EM (1985) Characterization of the binding properties and retrograde axonal transport of monoclonal antibody directed against the rat nerve growth factor receptor. J Cell Biol 101: 1100-1106.

Taniuchi M, Schweizer JB, Johnson EM (1986) Nerve growth factor receptor molecules in rat brain. Proc Natl Acad Sci USA 83:19501954.

Whittemore SR, Ebendal T, Lärkfors L, Olson L, Seiger $\AA$, Strömberg I, Persson H (1986) Developmental and regional expression of $\beta$ nerve growth factor messenger RNA and protein in the rat central nervous system. Proc Natl Acad Sci USA 83:817-821.

Williams LR, Varon S, Peterson GM, Wictorin K, Fischer W, Björklund A, Gage FH (1986) Continuous infusion of nerve growth factor prevents basal forebrain neuronal death after fimbria-fornix transection. Proc Natl Acad Sci USA 83:9231-9235. 